\title{
Socio-economic factors affecting attitudes towards childbearing: A study of ever married couples in Kermanshah, Iran
}

\author{
Ezzdin Alidousti ${ }^{1,}$ Abdul Reza Adhami ${ }^{1 *}$, Shahla Kazemipour ${ }^{1}$ \\ 1. Humanistics School, North Tehran Branch, Islamic Azad University, Tehran, Iran
}

Received: 12 May 2021

Accepted for publication: 17 Augut 2021

[EPub a head of print-28 August 2021]

Payesh: 2021; 20 (4): 471- 485

\begin{abstract}
Objective (s): In recent years decreasing fertility in Iran has become one of the demographic problems which has attracted the attention of policymakers. The purpose of this study was to identify the association between socio-economic factors with childbearing tendency.

Methods: This was a cross sectional study. A sub-sample of data from the "2017 Iran Fertility Transition Survey" was used. The sample comprised of 374 ever married men and women aged 15-49 in Kermanshah, Iran. They were selected through the clustered sampling and the data was analyzed via SPSS 22 software using linear regression, Pearson correlation, independent $\mathrm{t}$ test, and one-way analysis of variance

Results: The results obtained from data analysis indicated no significant relationships between residency, housing, home size, employment, education and social class and attitudes toward childbearing ( $p>0.05)$. However, significant relationships between sex preference, gender, spouse age, birth interval, Internet consumption, birth space and attitudes toward childbearing was observed $(\mathrm{p}<0.05)$. Overall the result indicated that independent variables could explain $23 \%$ of variance of dependent variables.

Conclusion: The findings suggest that the ideal number of children of young couples is affected by their living conditions. So, the success of any potential population polices depends on the improvement of couples' living conditions.
\end{abstract}

Key words: Socio-economic status, Fertility, childbearing

\footnotetext{
* Corresponding author: Humanistics School, North Tehran Branch, Islamic Azad University, Tehran, Iran

E-mail: adhamiab@yahoo.com
} 
نشريه يُوهشكده علوم بهداشتى جهاددانشگاهى

\section{عوامل اجتماعى - اقتصادى موثر بر نكرش به فرزند آورى: مطالعه موردى زوجين در آستانه ازدواج درشهر كرمانشاه}

عزالدين على دوستى'، عبدالرضا ادهمى "* شهلا كاظمى يور'

ا. دانشكده علوم انسانى، دانشكاه آزاد اسلامى واحد تهران شمال، تهران، ايران

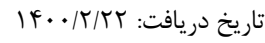

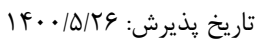

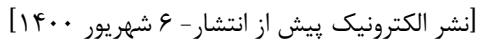

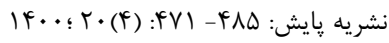

جكيده

مقدمه: در سالهاى اخير كاهش بارورى در ايران به يكى از مشكلات جمعيتى تبديل شده كه مورد توجه سياست كذاران قرار كرفته است. هدف از انجام اين

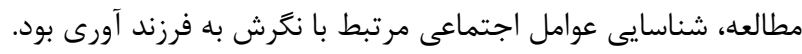

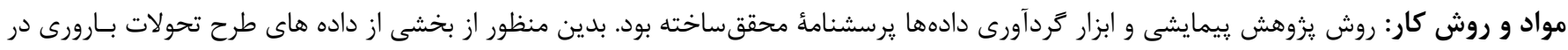

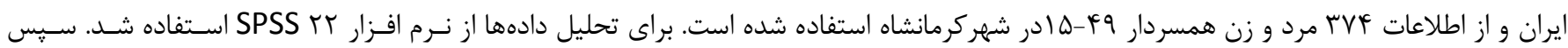

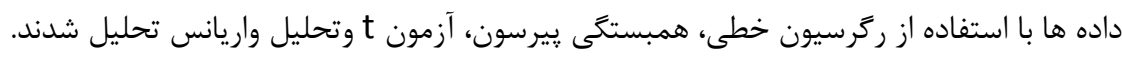

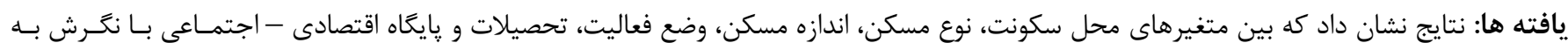

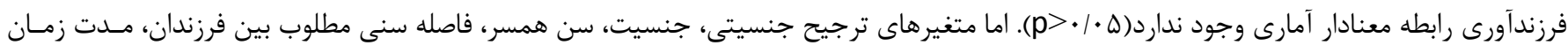

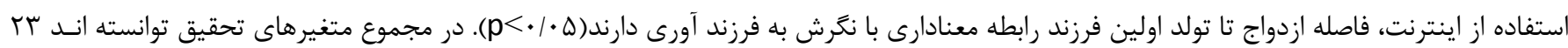

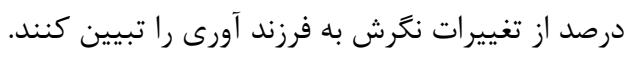

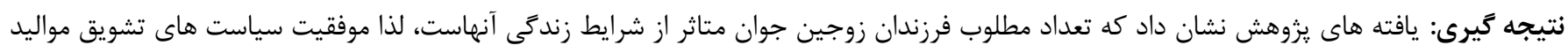

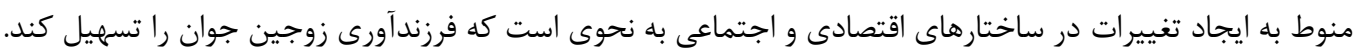
كليدوازه: پايعاه اجتماعى اقتصادى، بارورى، فرزندآورى

IR.IAU.TNB.REC.1400.018 كداخلاق 
ثروت خانوادگى اسـت. در جوامـع سـنتى كـهـ در وضـعيت بـارورى طبيعى به سر مى برند، فرزندان منافع اقتصادى دارند. جريان ثـروت

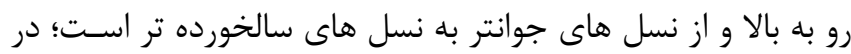

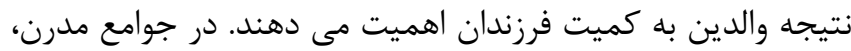

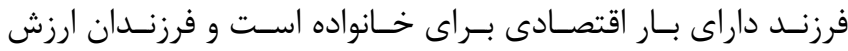

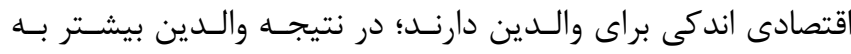

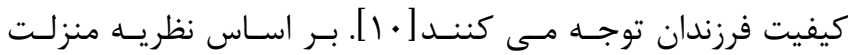
اجتماعى، خانواده باتوجه به يِيشرفت و ترقى حاصل شده در جامعـهـ

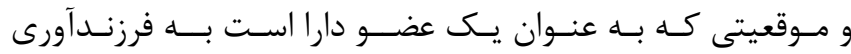

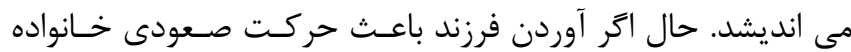

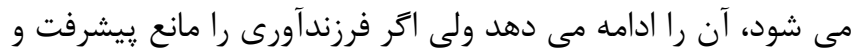

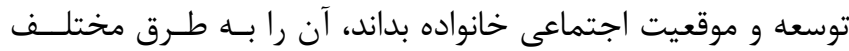

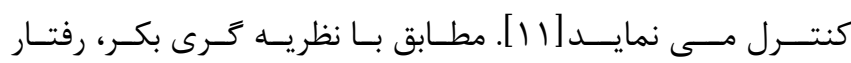
فرزندآورى خانواده ها محصول ارزيابى اقتصادى والـدين مبتنـى بــر

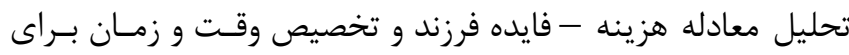

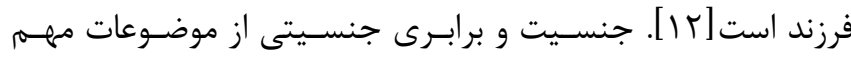
ارزشى - نتخرشى است كه در تحقيقات بارورى توجه زيـادى بــه آن شده است. مك دونالد تحت عنوان نظريـهـ برابـرى جنسـيتى نشـان

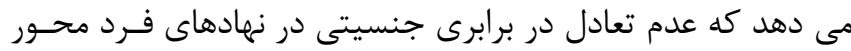

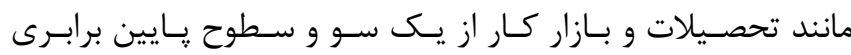
جنسيتى در نهادهاى خانواده محور به بارورى خيلى يايين در برخى له

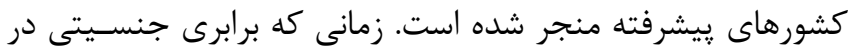

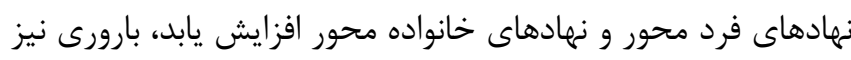

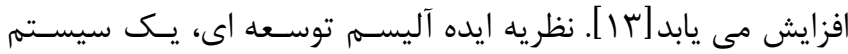
ارزشى و اعتقادى است كه بيان مى كنـد نخــــ هـاى اجتمــاعى و

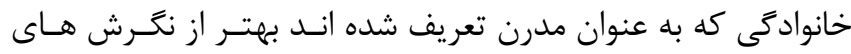

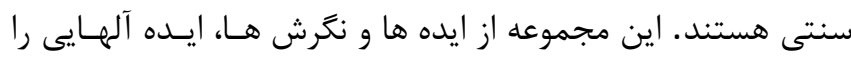
ايجاد مى كنند كه موجب تغييراتى در نخرش ها و رفتارهاى مرتبط

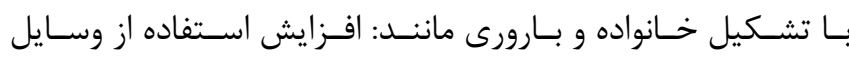

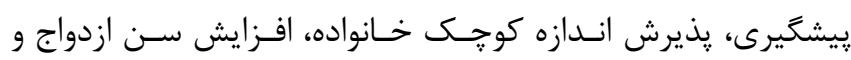
برابرى جنسيتى بيشتر شده اند. همجنين فناورى ارتباطات و رسانه هاى جمعى دانشى درباره اشكال جديد رفتار به تمـام نقـاط جهـان

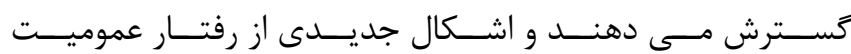

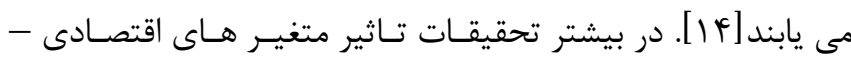

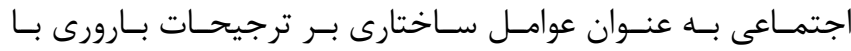

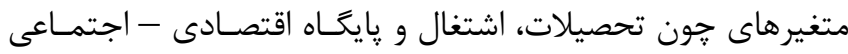

\section{مقدمه}

طبق گزارش سال IV • I سازمان ملل در مورد جشمم انداز جمعيـت

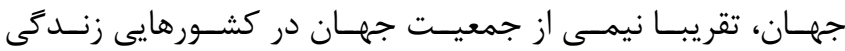
مى كنند كه بارورى زير سطح جانشينى دارند. در سال • • 19V ،

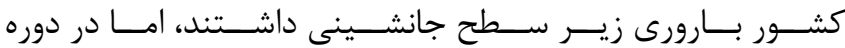

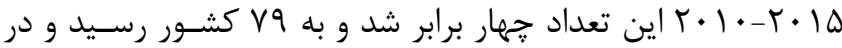

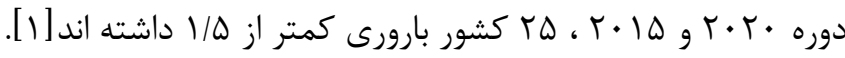

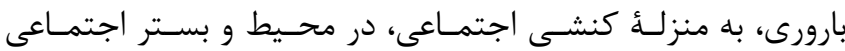

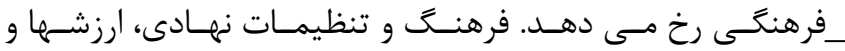
هنجارهاى مرتبط با بارورى را شكل مى دهند. جامعهُ ايسران تحــول

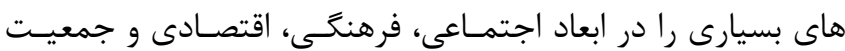
شناختى يشت سر گذاشته است. يكى از اين تحول ها، كاهش سريع بارورى و فراحيرى اين كاهش در تمـام اسـتانها و منــاطق شـهرى و

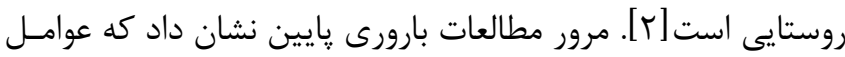

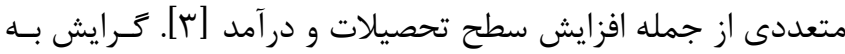

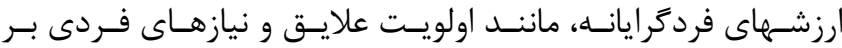

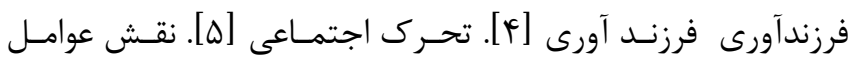
ارزشى و فرهنكى [ع]. ييش فرض تاثير گذارى متغيرهاى اقتصـادى -

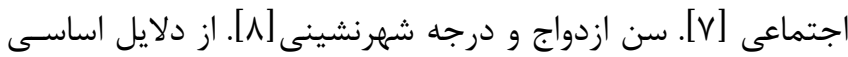
بارورى پايين است. بارورى يكى از عوامل سه كانه تغيير و تحـولات

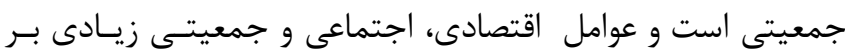
تصميم كيرى زوجين در فرزند آورى و رفتار بـارورى زنسان موثرنـد.

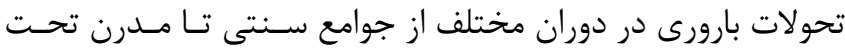

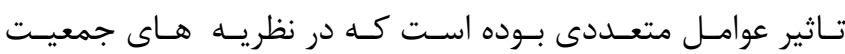
شناختى به تناسب هر دوره توسط جمعيـت شناسـان بـهـ آن اشـاره شده است. اولين تبيين جامع تغيير بارورى توسط نوتشتاين صورت

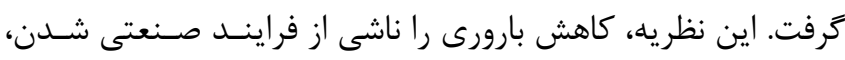

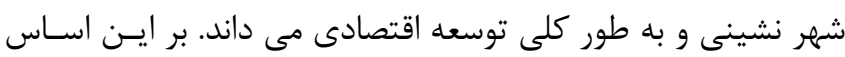

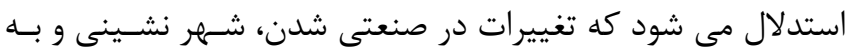
طور كلى توسعه اقتصادى، ابتدا باعث كاهش مرگ و مير مسى شـود،

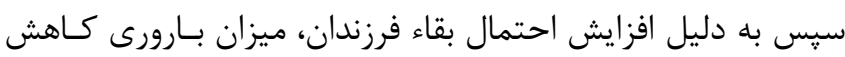
مى يابد. متغير هاى تحقيق (محل سكونت، تحصيلات، اشتغال) كـهـ

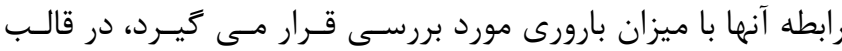

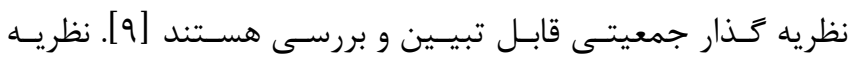

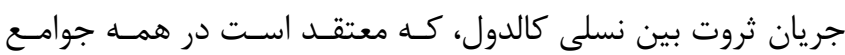

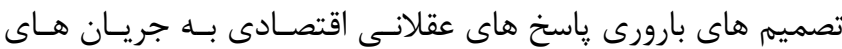


سياسـت كـذارى هــاى جمعيتـى متناسـب بــا بسـترهاى اقتصـادى،

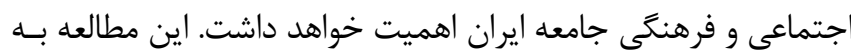

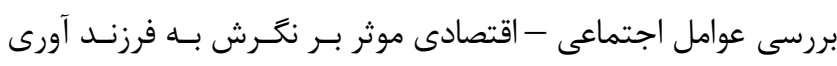

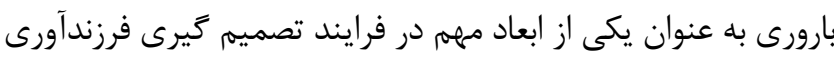

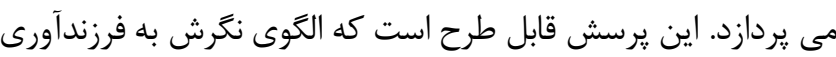

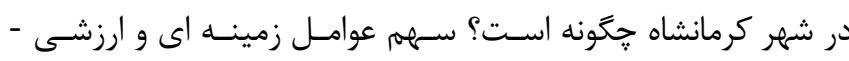

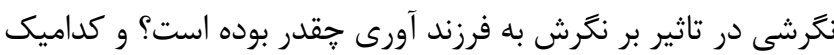

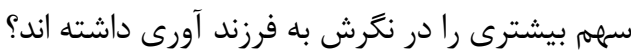

\section{مواد و روش كار}

در يزوهش حاضر كه به لحاظ روش كمى، و از نوع تحليل داده هاد هاى

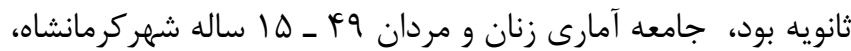

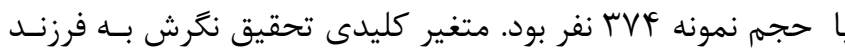

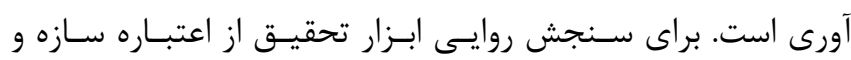

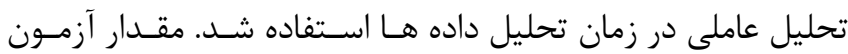

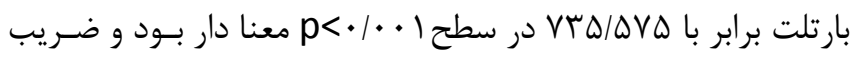

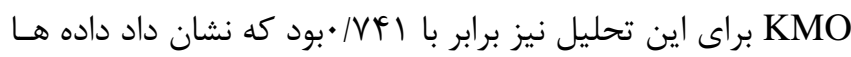

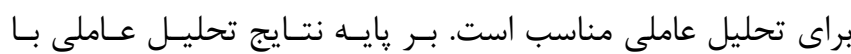

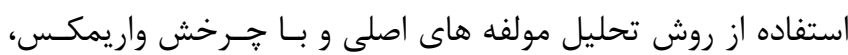

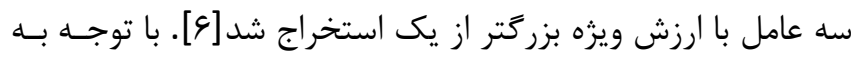

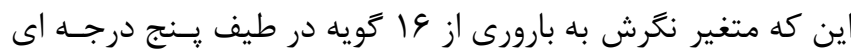

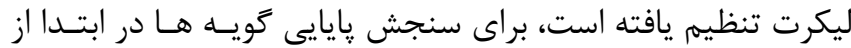

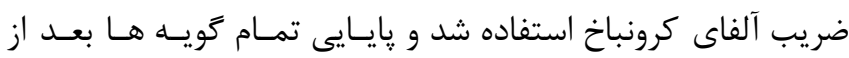

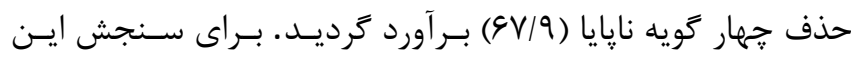

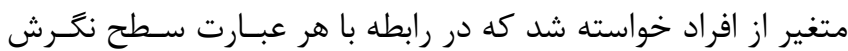

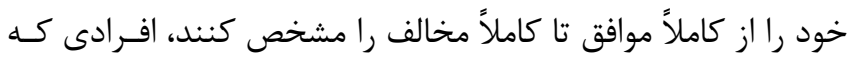

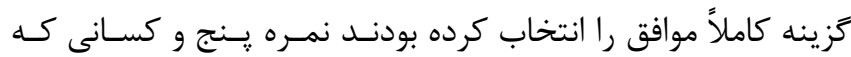

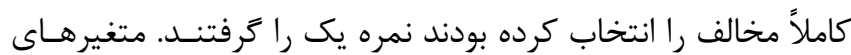
مستقل در اين تحقيق شامل جنسـيت، سـطح تحصـيلات، در آمـد،

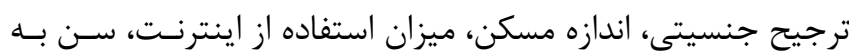

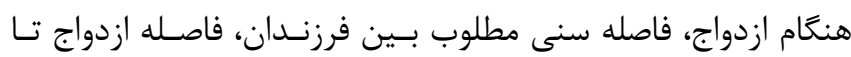

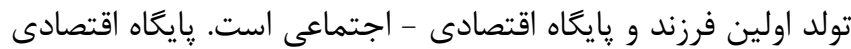
- اجتماعى شاخصى تركيبـى اسـت كـه تجربــــ كـارى و موقعيست

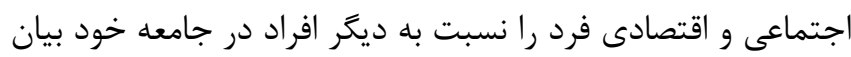

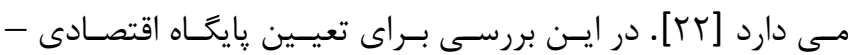

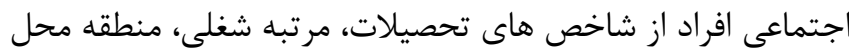

بررسى شده است. رابطه ميان بايكاه اقتصـادى - اجتمـاعى و تعـداد

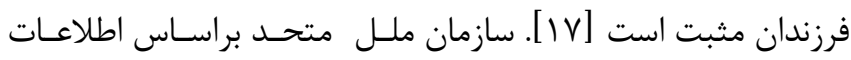

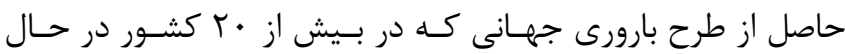
توسعه اجرا شد، مطالعاتى داشته است. نتايج اين مطالعات نشان داد داد داد داد داد كه بين سن ازدواج، درجه شهرنشينى، سـالهاى تحصـيل و بـارورى إنى

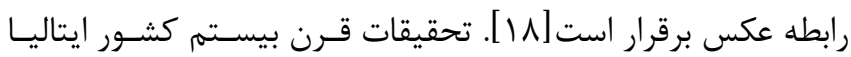
نشان داد كه رابطه منفى بين بارورى و طبقه شغلى، درآمد و سـطح

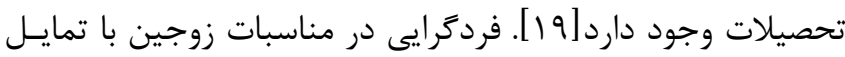

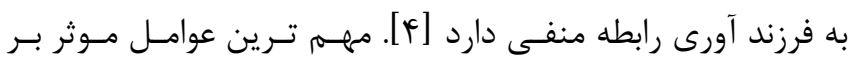

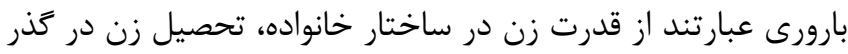

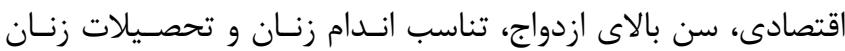

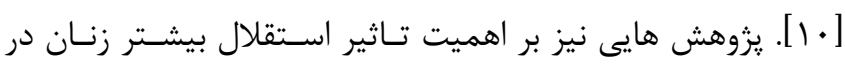

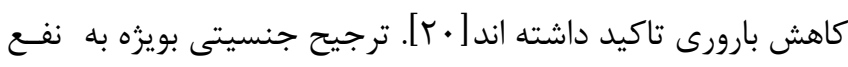
فرزندان يسر در ايران و بسيارى از كشورهاى جهان وجـود داشـته و

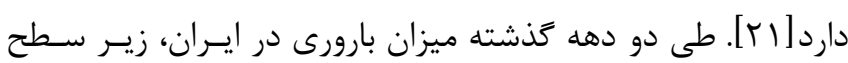

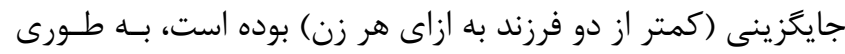

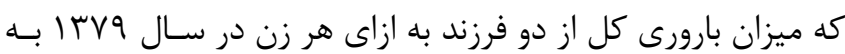

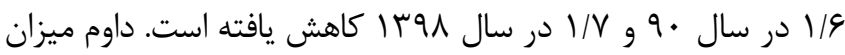

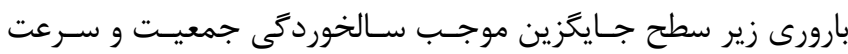

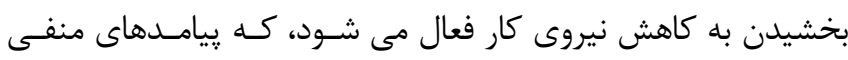

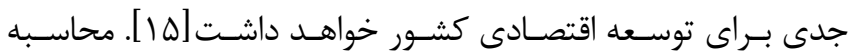
شاخص ميزان بارورى كل TFR استان كرمانشاه كه در جلسه كميتـهـ

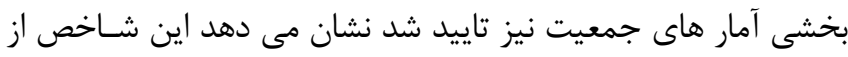

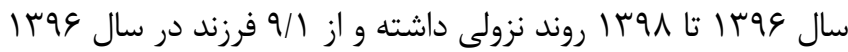
به 9/1 در سال 199 رسيده است[ع|]. اكثر مطالعاتى كه در سال هاى اخير در حوزه بارورى در ايران انجام كرفته معطوف به تعداد فرزنـدان به دنيا آمده زنان است و مشخص نيست كه آيا نكرش بارورى آنان نيز نيز

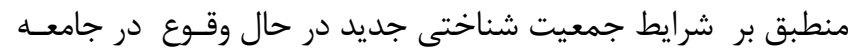

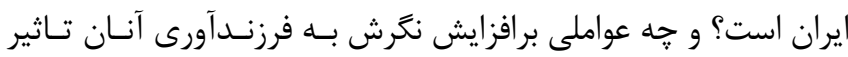

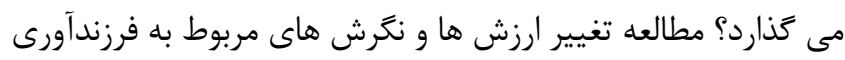

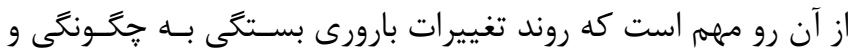

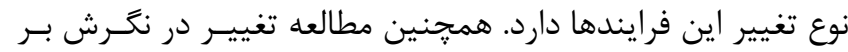

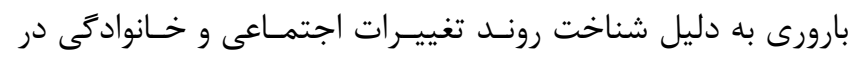

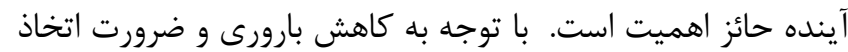

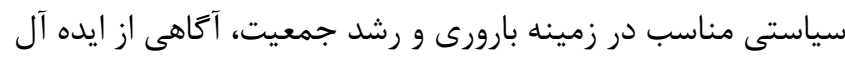

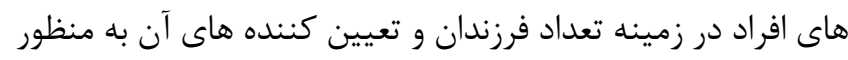


از ياسخ گَويانى بود كه قائل بـه تـرجيح جنسـيتى نيسـتند. بيشـتر ياسخ گويان تمايل به فاصله سنى مطلوب بين ه-r سال داشـتند و

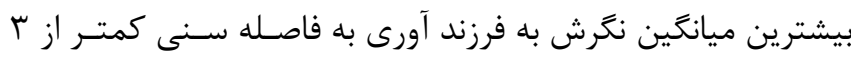

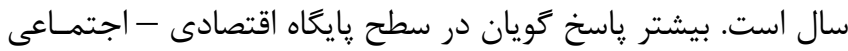
متوسط قرار دارند، هر جه يُاسخكَويان از موقعيت بالاترى برخــوردار

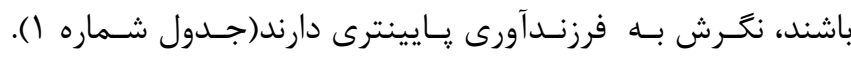

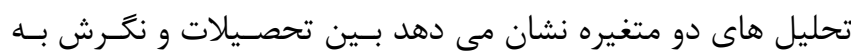

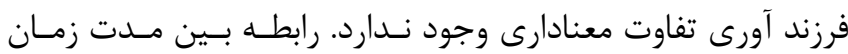
استفاده از اينترنت و نكرش به فرزند آورى نشان مى دهد دهد كه تفاوت

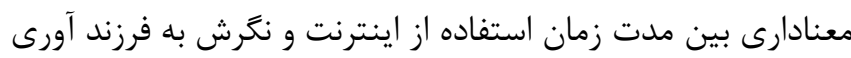
وجود دارد؛ بطوريكه هرجه مدت زمان اسـتفاده از اينترنـت در بــين

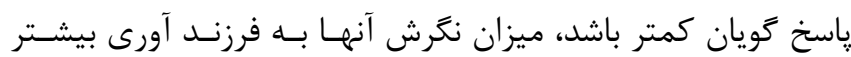

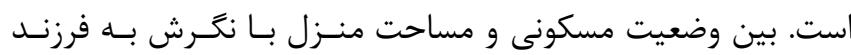
آورى تفاوت معنادارى وجود ندارد. بين متغير فاصله ازدواج تا تولـد اولين فرزند و نكرش به فرزند آورى از نظر آمارى تفـاوت معنـادارى وجود دارد. براى مشخص شدن تفاوت معنادار بـين ميـانگين هـا از

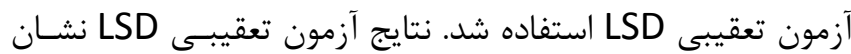

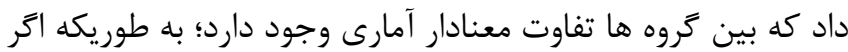

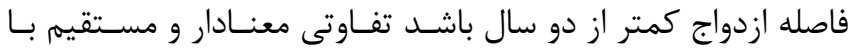
نكرش به فرزند آورى دارد، جنانجه فاصله ازدواج تا تولد اولين فرزند

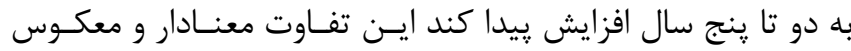

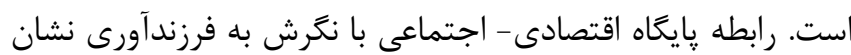

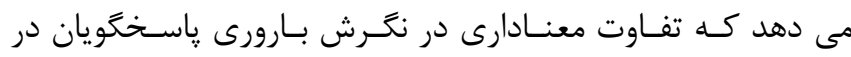

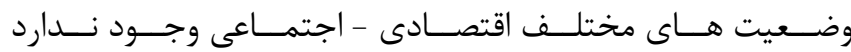
(جدول شماره ץ). رابطه بين سن زوجين و فاصله سنى مطلوب بين

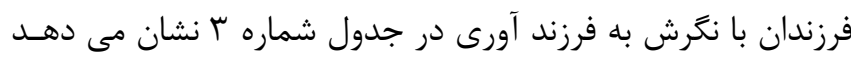

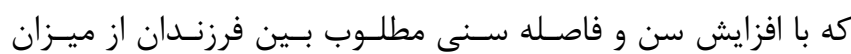

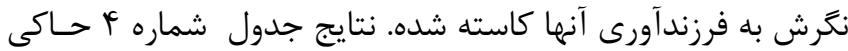

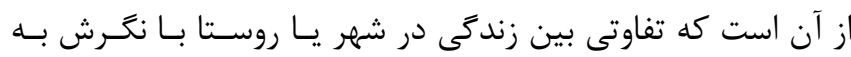

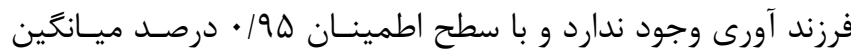

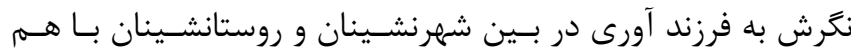
مشابه هستند. بين ترجيح جنسيتى و نكرش به فرزند آورى تفـاوت

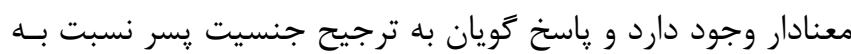

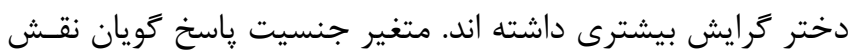
تعيين كننده اى بر ترجيح فرزند دختر و تـرجيح فرزنـد يسـر دارد. ترجيح هاى جنسيتى بين مردان برجسته و جشمگير است، نسـبت
سكونت، نوع منزل مسكونى و درآمد ياسخ گويان بهره گرفتـه شـده

يافتهها

توزيع فراوانى و درصد اطلاعات جمعيت شناختى شـركت كنـــــــــان

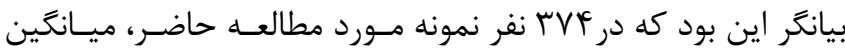

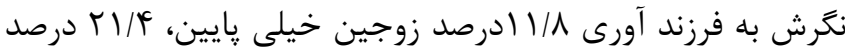

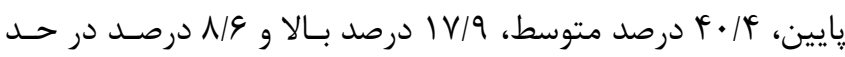

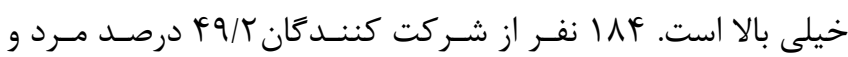

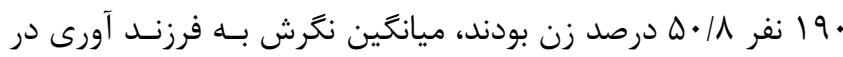

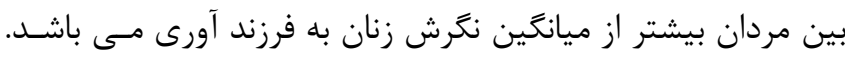

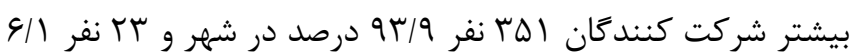

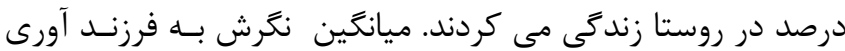

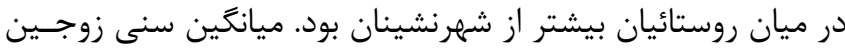

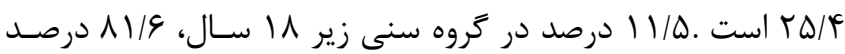

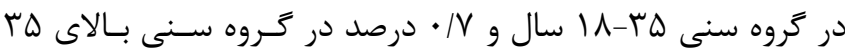

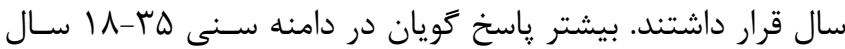

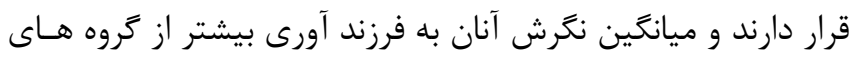

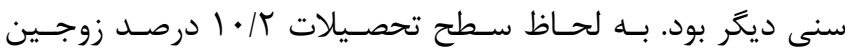

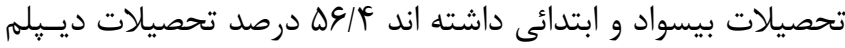

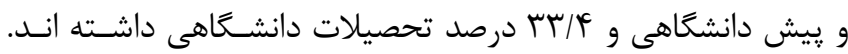

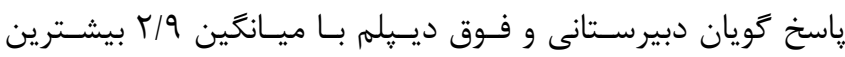

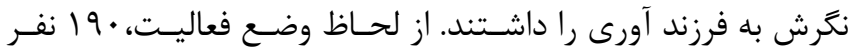

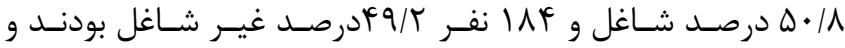

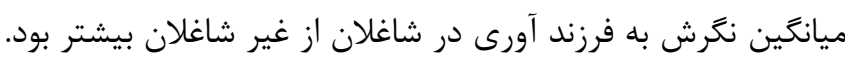

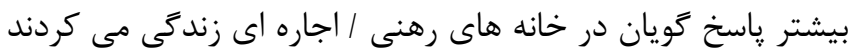

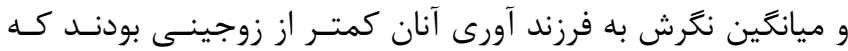

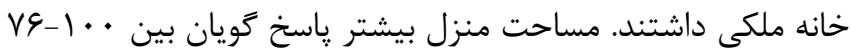

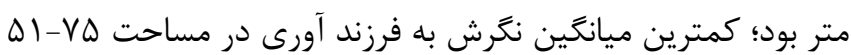

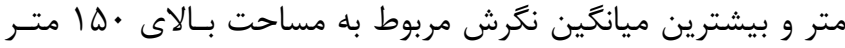

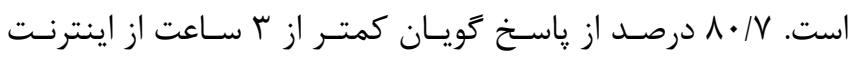

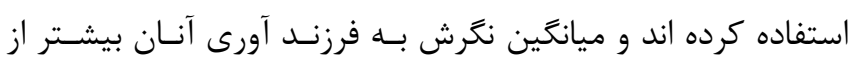

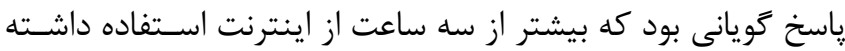

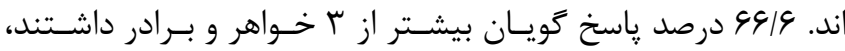

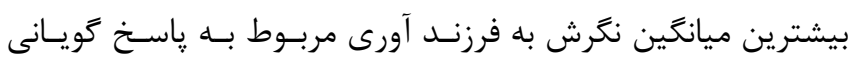

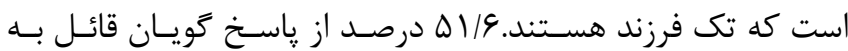
ترجيح جنسيتى بودند و ميانكَين نكَرش آنان به فرزند آورى بيشـتر 
در حالى كه متغير ترجيح جنسيتى كمترين تاثير را بـر نـــش بــــ

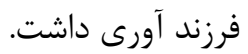
درجدول شماره 9 تاثير مستقيم و غيرمستقيم متغير هـاى مستـقل

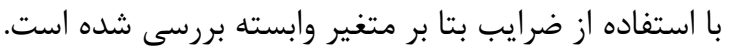

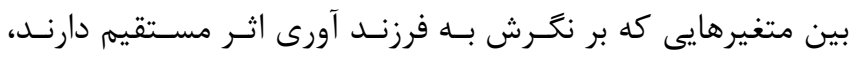

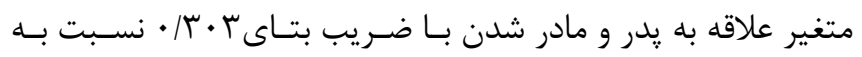

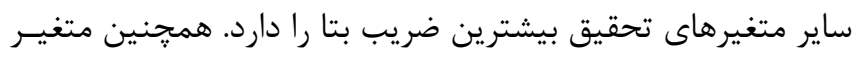

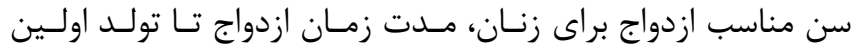

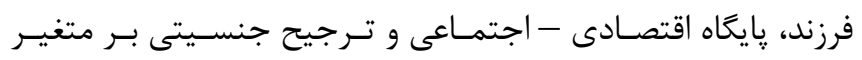

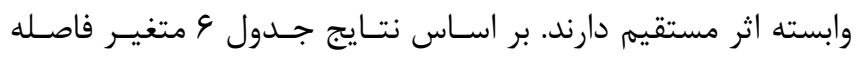

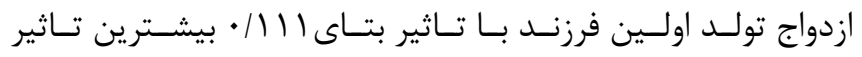

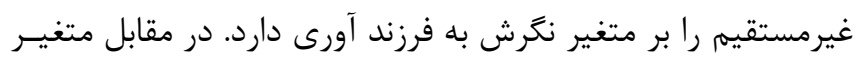

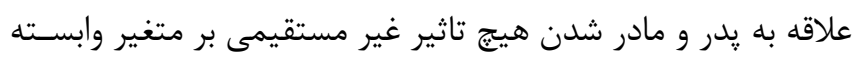

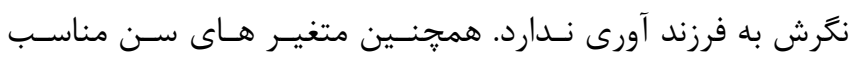

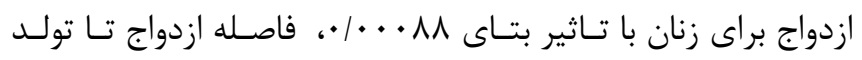

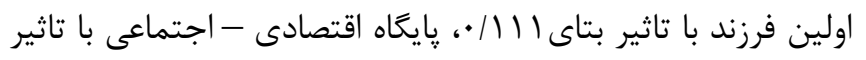

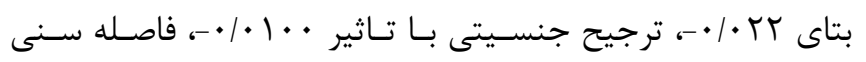

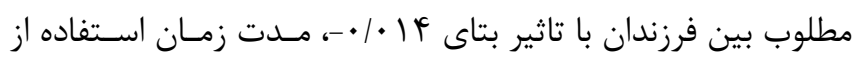

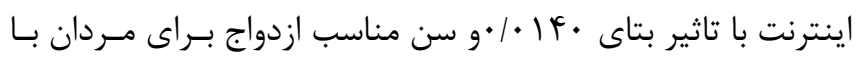

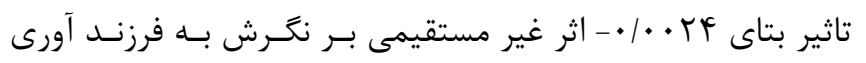

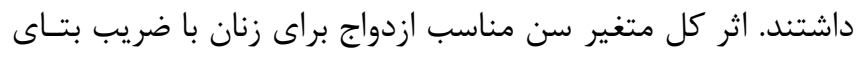

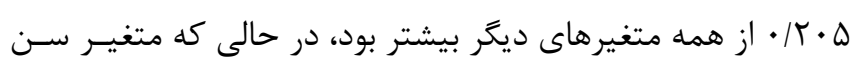

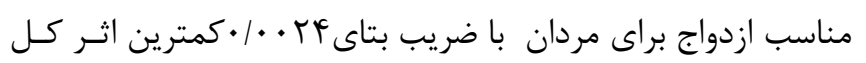

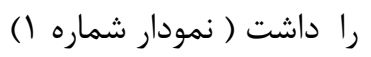

مردانى كه فرزند يسر را ترجيح مى دهند

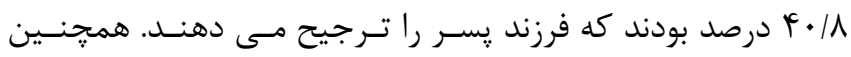

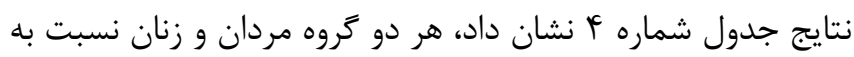

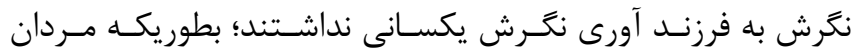

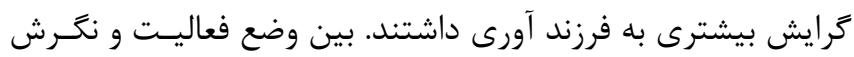

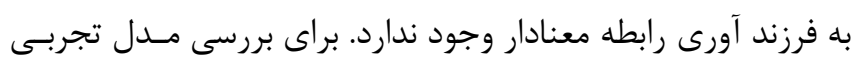

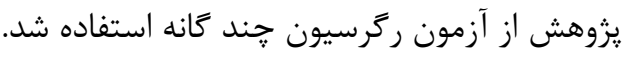

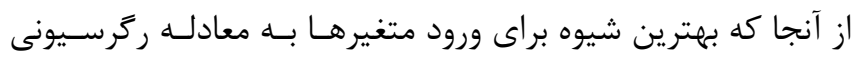

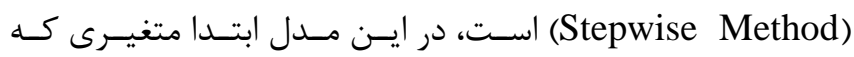
بيشترين همبستكى را با متغير وابسته دارد انتخاب مى شى شود. نتسايج حاصل از جدول شماره له نشان مى دهد كه ضريب همبستكى هن هند

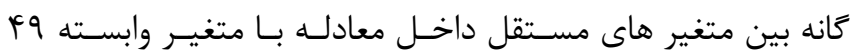

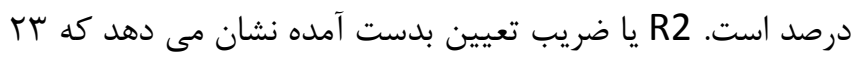

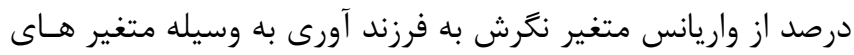

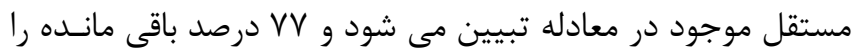

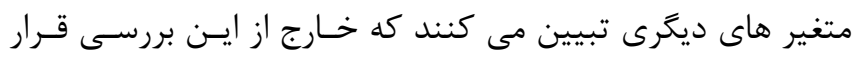

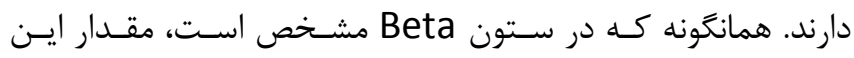

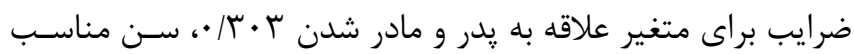

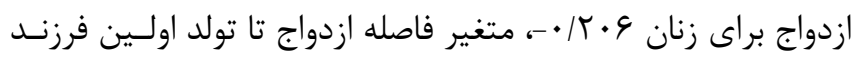

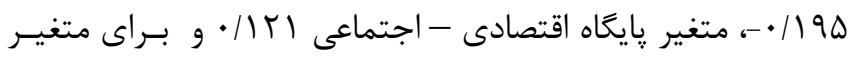

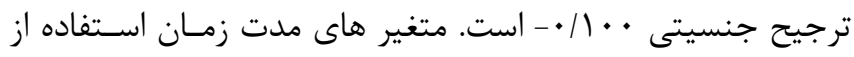

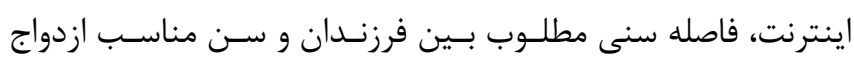

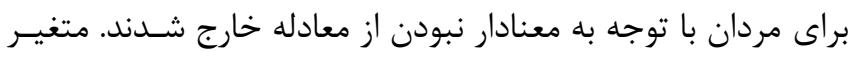

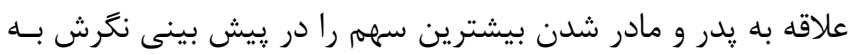

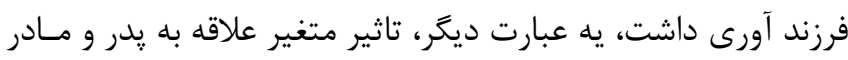
شدن بيشتر از ساير متغيرها بود. 
سال بيستم، شماره جههارم، مرداد ـ شهريور ..1F

جدول ا: وضعيت نكَر به فرزند آورى به تفكيك متغير هاى جمعيتى

\begin{tabular}{|c|c|c|c|c|c|c|c|}
\hline \multirow[t]{2}{*}{ ميانگين نگرش به فرزند آورى } & \multicolumn{2}{|c|}{ مجموع } & \multicolumn{2}{|c|}{ زنان } & \multicolumn{2}{|c|}{ مردان } & \multirow{2}{*}{+2} \\
\hline & درصد & تعداد & درصد & تعداد & درصد & تعداد & \\
\hline & & & & & & & محل سكونت \\
\hline$r / 1$ & $9 \% / 9$ & $r \Delta l$ & $9 r / 9$ & IVE & $9 \Delta / 1$ & IVD & شهر \\
\hline$r / r$ & $9 / 1$ & r & $V / F$ & if & $r / q$ & 9 & 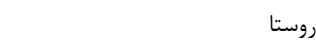 \\
\hline & & & & & & & سن \\
\hline $1 / 9$ & $|r /|$ & pr & $r m / l$ & r. & $1 / 9$ & $r$ & زير ^اسال \\
\hline$r / \cdot$ & $\Lambda \cdot 19$ & TAS & $V T / r$ & ITD & $\Lambda N / \Delta$ & 191 & از 1 تا هr سال \\
\hline $1 / 9$ & $V / r$ & re & $f / 9$ & $\wedge$ & $9 / 9$ & 11 & بالاى هَr سال \\
\hline & & & & & & & تحصيلات \\
\hline$r / \Lambda$ & $1 \cdot / r$ & ru & $|r /|$ & r & $\Lambda / r$ & 10 & بيسواد و ابتدائى \\
\hline$r / 9$ & $\Delta g / f$ & rII & $\Delta r / \varphi$ & $1 \cdots$ & $9 \cdot / r$ & 111 & دييلم و وِيش دانشكاهى \\
\hline$r / V$ & rr/e & ITD & $r \Delta / r$ & GV & $r 1 / \Delta$ & $\Delta \Lambda$ & ليسانس و بالاتر \\
\hline & & & & & & & وضع فعاليت \\
\hline$\mu /$ & $\Delta \cdot / \Lambda$ & 19. & $11 / 9$ & tr & $91 / \pi$ & 191 & شاغل \\
\hline$T / V$ & $r q / r$ & INF & $\Lambda N / F$ & $19 \Lambda$ & $\Lambda / V$ & 19 & غير شاغل \\
\hline & & & & & & & مالكيت منزل \\
\hline $\mathrm{r} / \cdot$ & FT/T & $1 \Delta \Lambda$ & $41 / 9$ & v9 & $F r / q$ & v9 & رهنى / اجاره اى \\
\hline$r / l$ & $r T / V$ & $\wedge \Delta$ & $r M / V$ & is & $r M / V$ & r. & ملكى \\
\hline$r / \cdot$ & $r \Delta / \cdot$ & $|r|$ & rF/V & 94 & $r \Delta / r$ & $9 D$ & رايگان/يدرى \\
\hline & & & & & & & مساحت منزل \\
\hline$r / l$ & $1 / 9$ & rt & $1 / 9$ & IV & $N / T$ & 10 & زير •له متر \\
\hline $1 / 9$ & $r F / l$ & 9. & $r V / F$ & QT & $r \cdot / V$ & rı & $\Delta I-V \Delta$ \\
\hline$r / \cdot$ & $4 \cdot 19$ & IDI & rN/q & VF & $F r / 9$ & vq & $V \varepsilon_{-1} \ldots$ \\
\hline$r / \cdot$ & $I V / F$ & $\varepsilon \Delta$ & $\mid N / F$ & ra & $19 / \pi$ & $r$. & $1 \cdot 1-10 \cdot$ \\
\hline$r / l$ & $9 / 1$ & ry & $9 / r$ & IT & $\mid r / \cdot$ & tr & $10 \cdot+$ \\
\hline & & & & & & & استفاده از اينترنت \\
\hline$r / 9$ & $\Lambda \cdot / V$ & $r \cdot r$ & $11 / 1$ & lQF & $\Lambda \cdot / 4$ & $\mid f \lambda$ & كمتر از ب ساعت \\
\hline$r / T$ & $\Delta / 9$ & $r \mid$ & $V / 4$ & If & $r / \Lambda$ & v & بين س تا و ساعت \\
\hline$r / V$ & $1 \pi / 9$ & $\Delta 1$ & $11 / 9$ & tr & $\mid \Delta / \Lambda$ & rq & بالاتر از وساعت \\
\hline & & & & & & & تعداد خواهر و برادر \\
\hline$r / r$ & $r / F$ & 9 & $r / 9$ & $\Delta$ & $r / T$ & r & تك فرزند \\
\hline$r / V$ & זा/. & 119 & $r \Delta / \Lambda$ & $9 \Lambda$ & $r \& / 1$ & $\mu \lambda$ & $r$ \\
\hline$r / 9$ & 9919 & rFq & $91 / 9$ & $11 \mathrm{~V}$ & $V I / V$ & IrT & $r_{+}$ \\
\hline & & & & & & & ترجيح جنسيتى \\
\hline$r / r$ & $01 / 9$ & 194 & $F F / T$ & NF & $\Delta 9 / r$ & $1 \cdot 9$ & بله \\
\hline$T / V$ & $r N / F$ & $|1|$ & $\Delta \Delta / \Lambda$ & 1.9 & $\varphi \cdot / \Lambda$ & $v \Delta$ & خير \\
\hline & & & & & & & فاصله ازدواج تا تولد اولين فرزند \\
\hline$r / 1$ & IN/V & $\vee \cdot$ & $11 / 9$ & re & $1 N / 0$ & rF & $r<$ \\
\hline$r / \cdot$ & $\Delta T / 1$ & 190 & $F \Delta / r$ & $\Lambda \notin$ & $\Delta q / r$ & 1.9 & $r-r$ \\
\hline$r / 4$ & $r q / 1$ & 1.9 & $r \Delta / \Lambda$ & 41 & $r T / r$ & \&I & $\Delta+$ \\
\hline & & & & & & & فاصله سنى مطلوب بين فرزندان \\
\hline$r / l$ & TN/I & $1 \cdot 0$ & $r / V$ & $i \Delta$ & Tr/Q & 4. & $r<$ \\
\hline$r / \Lambda$ & $p+/ 1$ & 190 & $F F / T$ & $\Lambda f$ & $F \varphi /$ & $\wedge 1$ & $r-\Delta$ \\
\hline$r / V$ & $r V / \Lambda$ & $1 \cdot 4$ & $r T / 1$ & 4) & $r m / F$ & pr & $\omega_{+}$ \\
\hline$r / 9$ & $r q / q$ & 114 & TN/F & $\Delta f$ & $r / / \Delta$ & $\Delta \wedge$ & يايين \\
\hline$r / 9$ & $\Delta \Delta / r$ & $r \cdot V$ & $\Delta \& / \pi$ & $1 \cdot v$ & $\Delta F / T$ & $1 \cdots$ & متوسط \\
\hline$r / \Lambda$ & $\mid f / V$ & $\Delta \Delta$ & $10 / \Gamma$ & rq & $|f /|$ & re & بالا \\
\hline
\end{tabular}




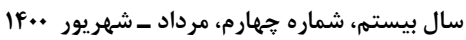

نشريه يثروهشده علوم بهداشتى جهاددانشًاهي

جدول r: نتايج تحليل واريانس بين متغير هاى اقتصادى - اجتماعى و جمعيتى با نكَرش به فرزند آورى

\begin{tabular}{|c|c|c|c|c|c|}
\hline سطح معنادارى & آزمون F & ميانغين & تعداد & طبقات & \multirow{4}{*}{ تحصيلات } \\
\hline \multirow{3}{*}{$\cdot / 1 \Delta \Delta$} & \multirow{3}{*}{ l/AVI } & $r / \Lambda$ & rᄉ & بيسواد و ابتدايى & \\
\hline & & $r / 9$ & MII & دييلهم و پيش دانش & \\
\hline & & $T / V$ & $1 T \Delta$ & ليسانس و بالاتر & \\
\hline \multirow{5}{*}{$\cdot 1 \cdot 99$} & \multirow{5}{*}{ F/VT } & $r / \Lambda$ & rVf & كل & \multirow{5}{*}{ مدت زمان استفاده از اينترنت } \\
\hline & & $r / 9$ & $r \cdot r$ & كمتر از r ساعت & \\
\hline & & $r / T$ & rI & بين r تا و ساعت & \\
\hline & & $T / V$ & QI & بالاتر از 9 ساعت & \\
\hline & & $r / 9$ & rVF & كل & \\
\hline \multirow{3}{*}{.1948} & \multirow{3}{*}{$\cdot / \cdot v V$} & $r / \cdot$ & 101 & رهن/اجاره & \multirow{3}{*}{ وضعيت مسكونى } \\
\hline & & $r / 1$ & $\Lambda \Delta$ & ملكى & \\
\hline & & $r / \cdot$ & $|r|$ & رايكان/يدرى & \\
\hline \multirow{7}{*}{$\cdot / 1 F \Delta$} & \multirow{7}{*}{ I/VTI } & $r / \cdot$ & rVt & كل & \multirow{7}{*}{ 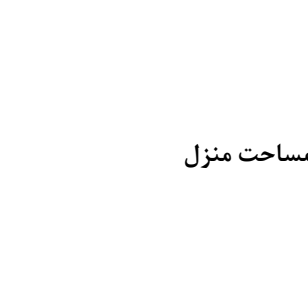 } \\
\hline & & $r / T$ & rt & كمتر از •له متر & \\
\hline & & $\mathrm{r} / \cdot$ & 9. & $\Delta I-V \Delta$ & \\
\hline & & $r / 1$ & lQT & $v \varepsilon-1 \cdots$ & \\
\hline & & $r / 1$ & 90 & $1 \cdot 1-10$ & \\
\hline & & $r / r$ & ry & بيشتر از • لها متر & \\
\hline & & $r / 1$ & rVf & كل & \\
\hline \multirow{3}{*}{$\cdot 1 \cdots$} & \multirow{3}{*}{$\mid \psi / \ldots$} & $r / 1$ & $\checkmark \cdot$ & كمتر از r سال & \multirow{3}{*}{ فاصله ازدواج تا تولد اولين فرزند } \\
\hline & & $\%$ & 190 & بين r تا F سال & \\
\hline & & $t / f$ & 1.9 & بالاى ه سال & \\
\hline \multirow{5}{*}{$\cdot / V \Delta \Lambda$} & \multirow{5}{*}{$\cdot / T V \Lambda$} & $r / \Lambda$ & rVF & كل & \multirow{5}{*}{ بايكاه اقتصادى - اجتماعى } \\
\hline & & $r / 9$ & 114 & طبقه پايين & \\
\hline & & $r / 9$ & $r \cdot v$ & طبقه ميانى & \\
\hline & & $r / \Lambda$ & $\Delta \Delta$ & طبقه بالا & \\
\hline & & $r / \Lambda$ & rVF & كل & \\
\hline
\end{tabular}

جدول ז: نتايج همبستكى يِيرسون بين سن و فاصله سنى مطلوب بين فرزندان با نكرش به فرزند آورى

\begin{tabular}{|c|c|}
\hline سطح معنادارى & مقدار يِيرسون \\
\hline .1 .19 & $-\cdot / 1 T \Delta$ \\
\hline $.1 \cdot T F$ &.$- / 11 \mathrm{~V}$ \\
\hline
\end{tabular}

\begin{tabular}{|c|c|c|c|c|c|}
\hline سطح معنادارى & آزمون & ميانگين & فراوانى & & \\
\hline \multirow[t]{2}{*}{$\cdot / D S V$} & $-\cdot|\Delta|$ & r/А & $r \Delta l$ & شهر & محل سكونت \\
\hline & & $r / \cdot \varphi^{r}$ & r & ل روستا & \\
\hline \multirow[t]{2}{*}{$\cdot 1 \cdot \cdot r$} & T/AV & $r / \cdot \Delta$ & $19 \pi$ & بله & ترجيح جنسيتى \\
\hline & & $T / V T$ & $|1|$ & خير & \\
\hline \multirow[t]{2}{*}{$\cdot 1 \cdot r$} & $r / l V$ & $r / \cdot \Lambda$ & INF & مرد & جنسيت \\
\hline & & $r / V \Delta$ & 19. & زن & \\
\hline \multirow[t]{2}{*}{.$/ 1 T 4$} & $1 / \Delta \Delta$ & $r / \cdot$ & 19. & شاغل & وضع فعاليت \\
\hline & & $T / V$ & INF & غير شاغل & \\
\hline
\end{tabular}

جدول ه: آزمون تحليل ركر سيون براى مقايسه يِش بينى متغيرهاى نكرش به فرزند آورى

\begin{tabular}{|c|c|c|c|c|c|c|}
\hline $\mathbf{R}^{2}$ & $\mathbf{R}$ & P-Value & $\mathbf{T}$ & Beta & B & \\
\hline$\cdot / 1 \Delta F$ & $\cdot /$ /49 & $\cdot 1 \cdot$ & $9 / 1$ & $\cdot \pi \cdot r$ & $1 / 94$ & علاقه به يدر و مادر شدن \\
\hline$\cdot / 1 \wedge \vee$ & $\cdot /$ krV & $\cdot 1 \cdot$ & $-4 / \pi$ & $-\cdot / 4 \cdot 4$ & $-\cdot / 411$ & سن مناسب ازدواج براى زنان \\
\hline$\cdot / \pi 10$ & $\cdot|\& V|$ & $\cdot / \cdot r$ & $-r / 9$ & $-\cdot / 190$ & $-\cdot / A T V$ & فاصله ازدواج تا تولد اولين فرزند \\
\hline - ITTF & . /ANt &.$/ \cdot 14$ & $-T / Q$ &.$/|r|$ & $1 / \pi$ & مدت زمان استفاده از اينترنت \\
\hline . & . /4qr &.$|\cdot r|$ & $-t / 19$ & $-\cdot / 1 \cdot$ & $-1 / 49$ & ترجيح جنسيتى \\
\hline
\end{tabular}


سال بيستم، شماره جههارم، مرداد ـ شهريور ..1F

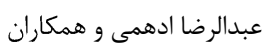

عوامل اجتماعى اقتصادى موثر بر ...

جدول 9: ميزان تاثير مستقيم و غير مستقيم و كل متغير هاى مستقل بر نكَرش به فرزند آورى

\begin{tabular}{|c|c|c|c|}
\hline 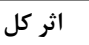 & اثر غير مستقيم & اثر مستقيم & \\
\hline$\cdot \pi \cdot r$ & $\begin{array}{ll}--- \\
-\end{array}$ & $\cdot / r \cdot r$ & علاقه به پيدر و مادر شدن \\
\hline$\cdot / r \cdot \Delta$ & $\cdot / \cdots \wedge \wedge$ & $-\cdot / r \cdot 4$ & سن مناسب ازدواج براى زنان \\
\hline$\% \cdot \Delta F$ &.$/ 111$ &.$- / 190$ & فاصله ازدواج تا تولد اولين فرزند \\
\hline .1 .99 &.$- / . r t$ & $\cdot /|r|$ & يايعاه اقتصادى - اجتماعى \\
\hline .111 & $-\cdot / \cdot 1 \cdot$ & $-\cdot / 1$. & ترجيح جنسيتى \\
\hline$\cdot / \cdot 14$ &.$- / .14$ & --- & فاصله سنى مطلوب بين فرزندان \\
\hline$\cdot \cdot \cdot r t$ & $-\cdot / \cdot r t$ & --- & سن مناسب ازدواج براى مردان \\
\hline .1 .14 &.$/ .14$ & --- & مدت زمان استفاده از اينترنت \\
\hline
\end{tabular}

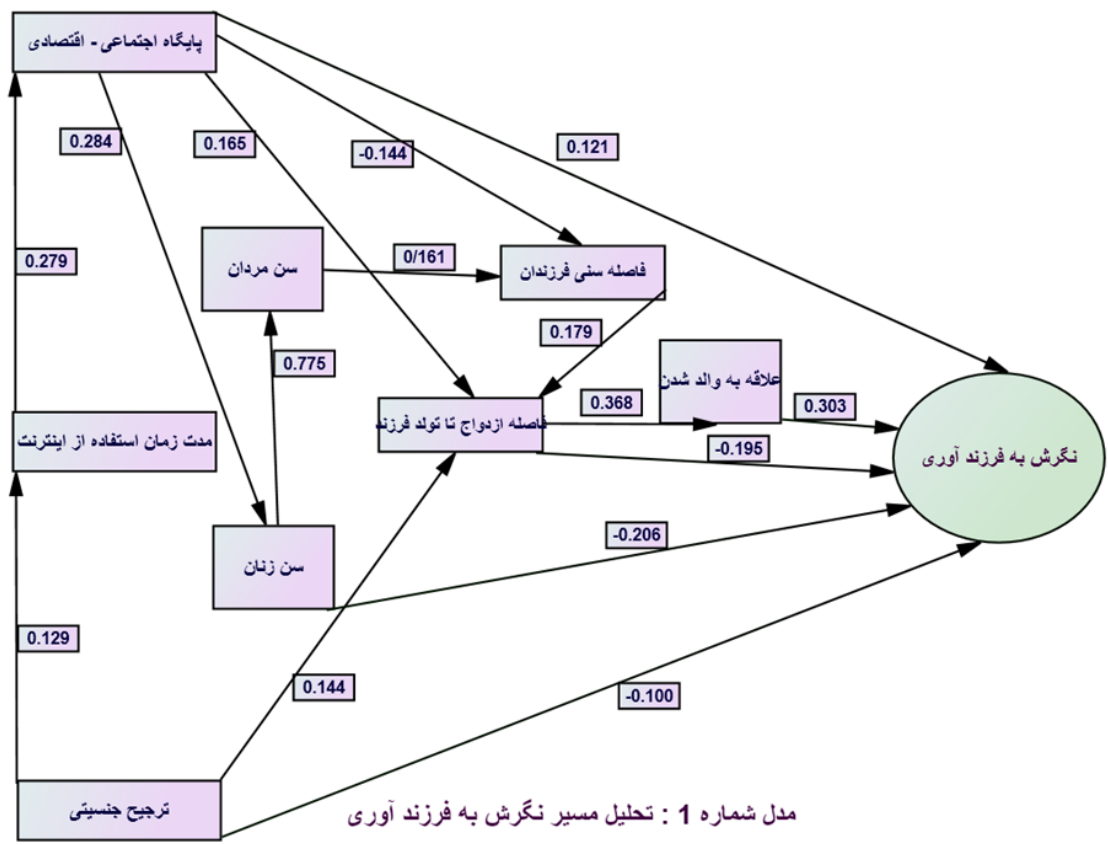

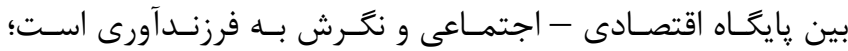
بحث و نتيجه گيرى

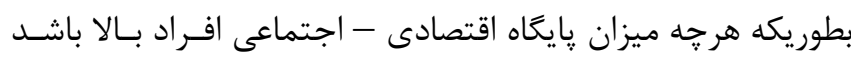

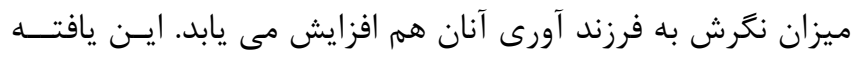

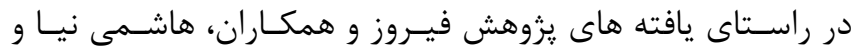
همكاران، ارجمند، سياهيوش و برومند نيست كه در يزوهش نشان

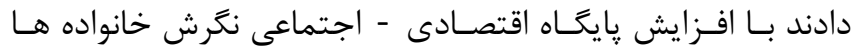

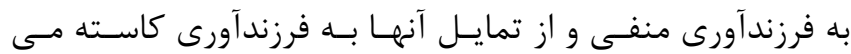

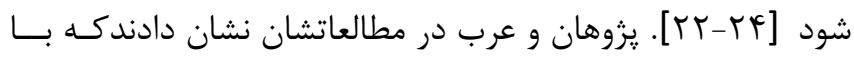

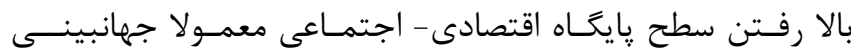

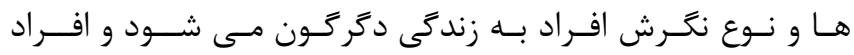
خواهـان سطح زنـدگى ايـده آل و نسبتا بالايى براى خود و فرزندان

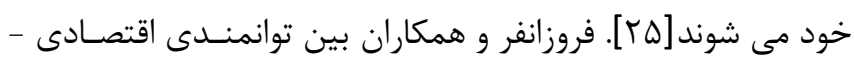

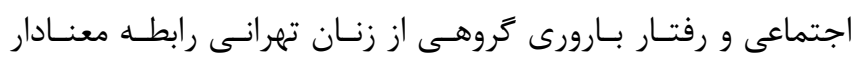

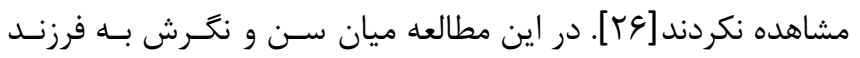
در يرهش حاضر از روش يِيمـايش اسـتفاده شـده اسـت. داده هــاى

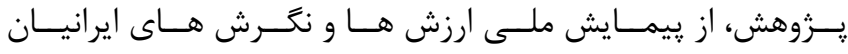
( موج سوم ) است. جمعيت مورد بررسى زوجـين در آسـتانه ازدواج

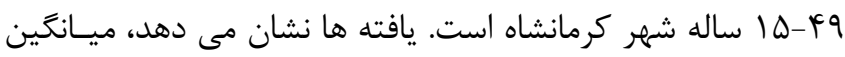

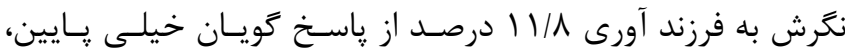

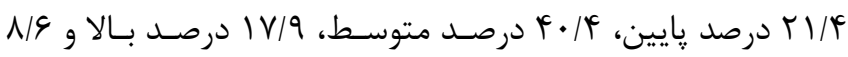
درصد در حد خيلى بالا است. در تحليل هاى دو متغيره رابطه ميان متغيرهاى زمينه اى و نحرش به فرزند آورى يافته ها نشان مى ده دهد كه بين متغيرهاى جمعيتى سن، جنسـيت، محـل سـكونت تفـاوت

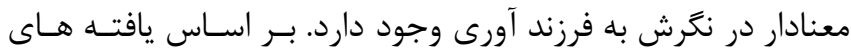
يزوهش در تحليل هاى دو متغيره بين يايخاه اقتصادى - اجتمـاعى

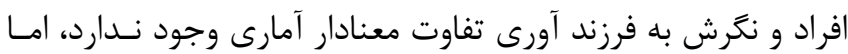

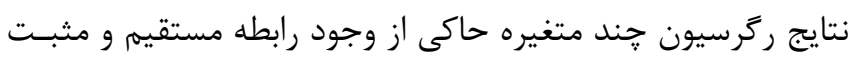


فرزندآورى تأثير بكذارد. يافته هاى يزوهش با يافته هاى منصـوريان

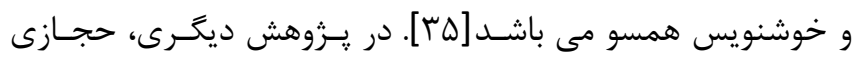

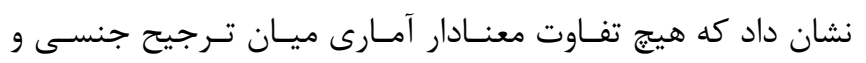

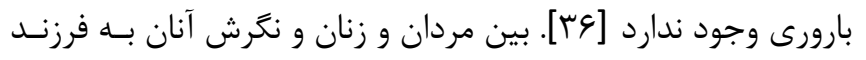

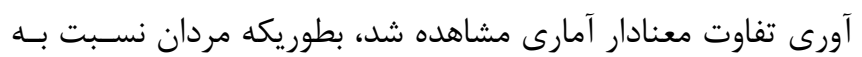

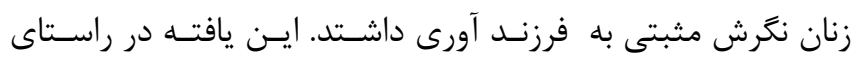

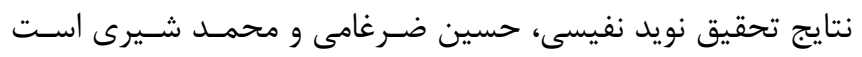

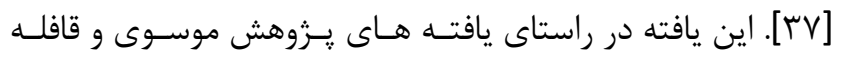

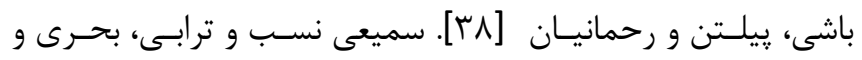

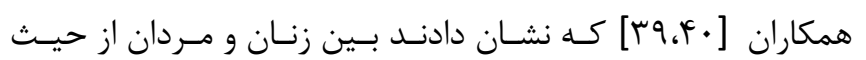

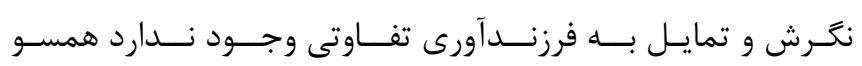

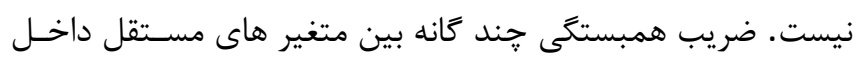

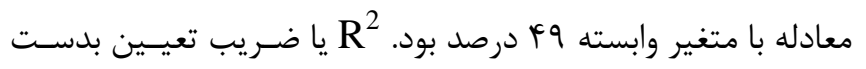

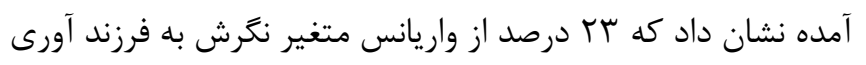

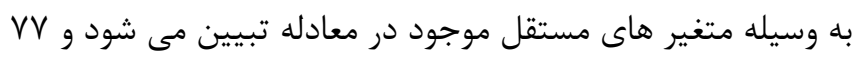

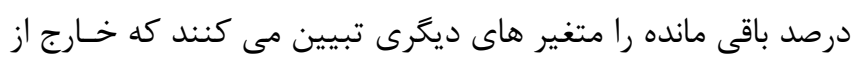

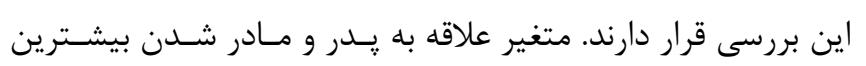

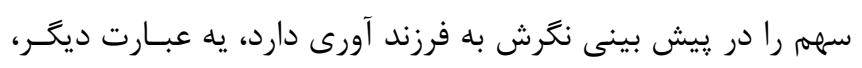

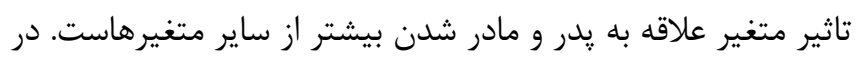

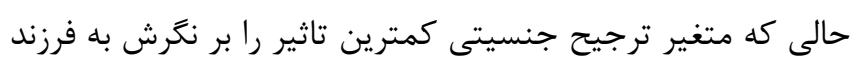

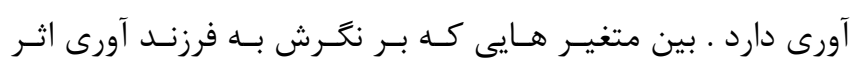

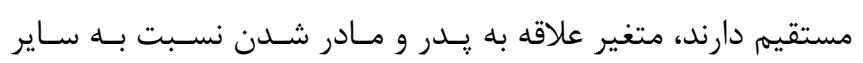

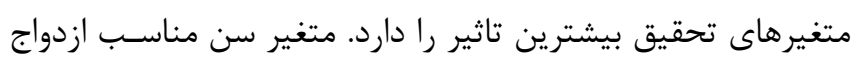

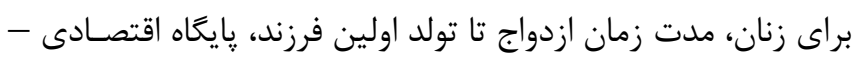

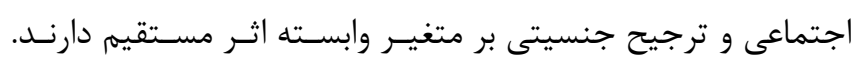

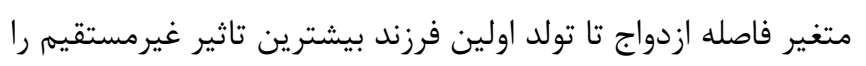

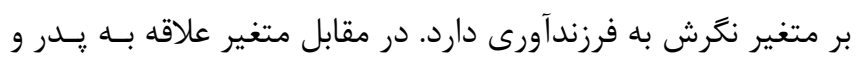

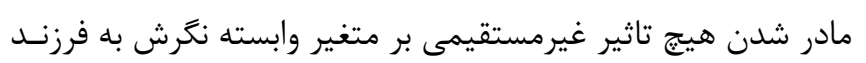

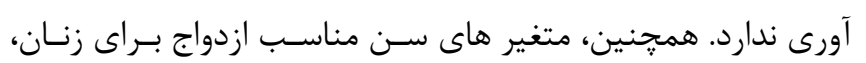

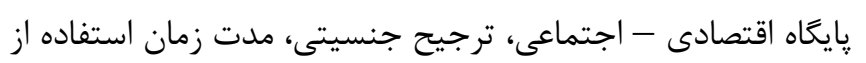

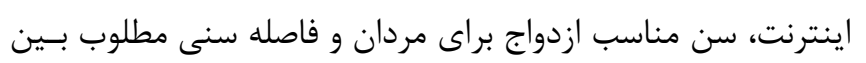

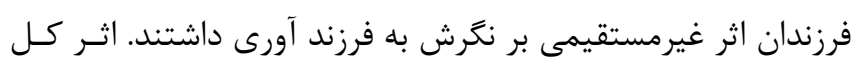

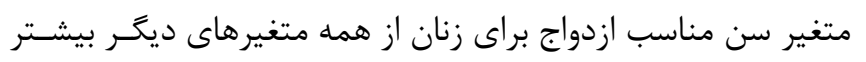

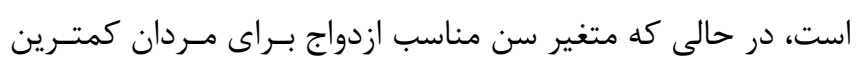

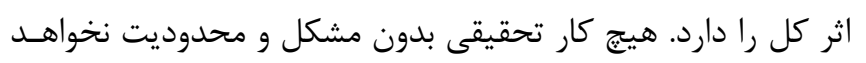

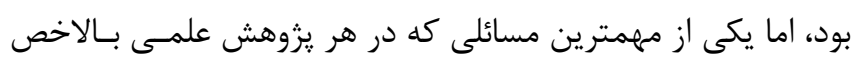

آورى رابطه منفى و معنادارى وجود داشت؛ هر جهه سن افراد بـالاتر

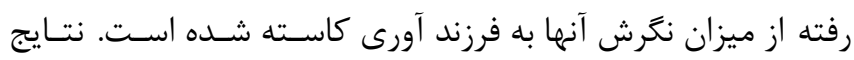

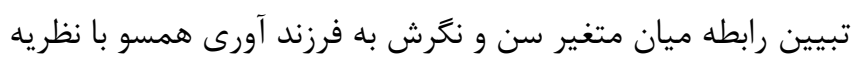

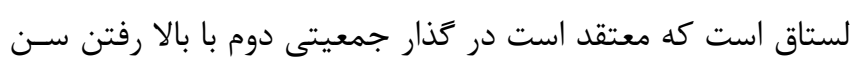

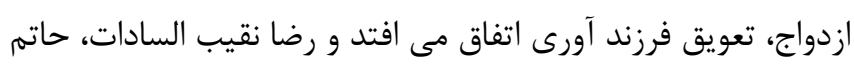

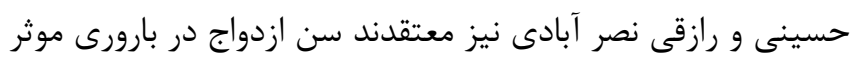

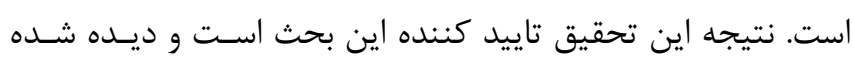

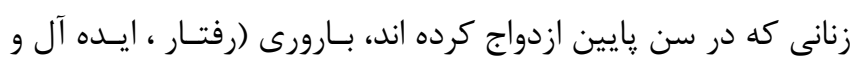

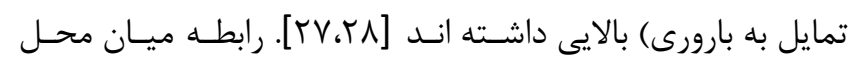

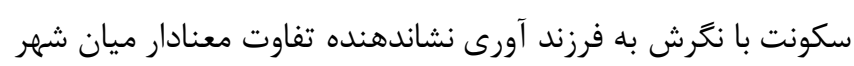

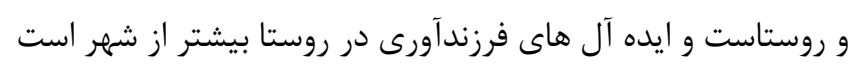

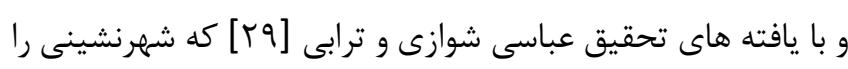

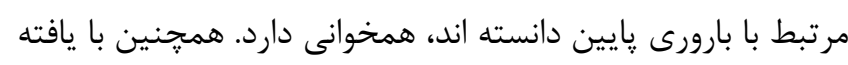

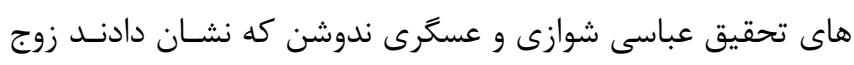

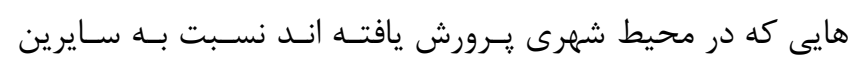

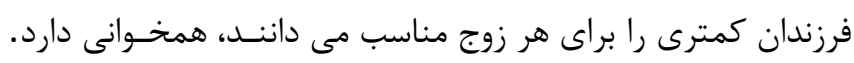

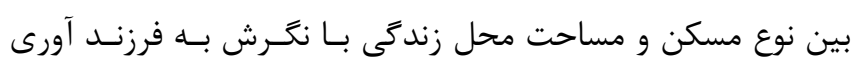

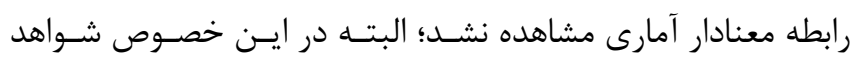

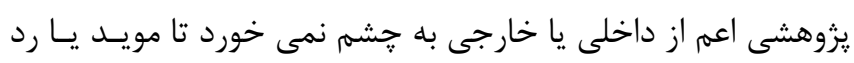

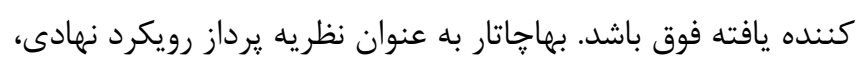

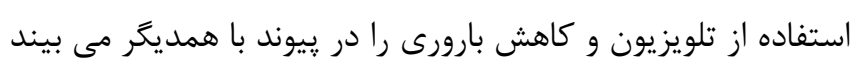

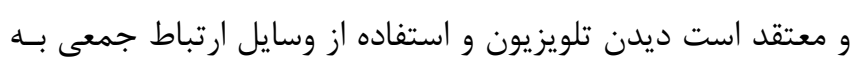

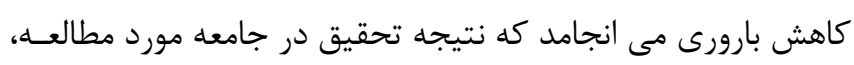

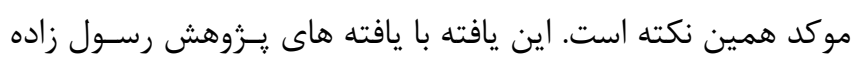

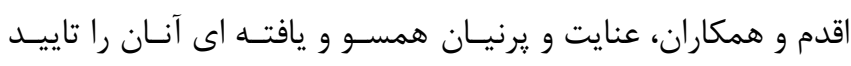

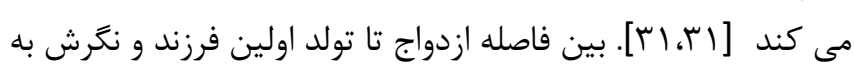

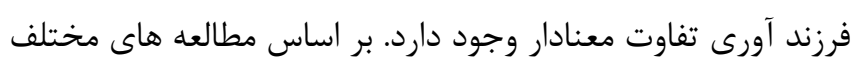

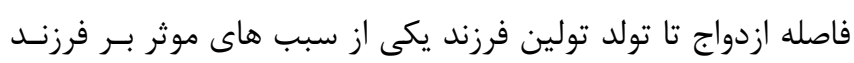

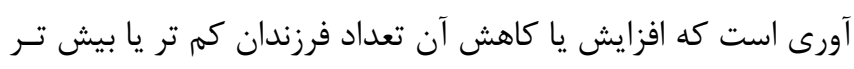

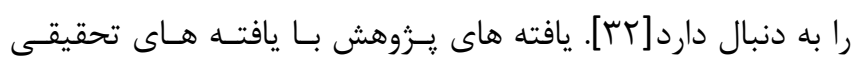

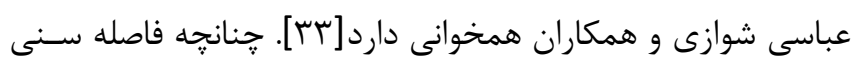

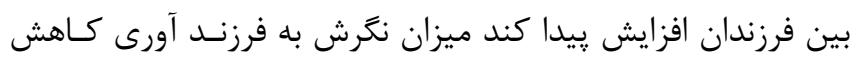

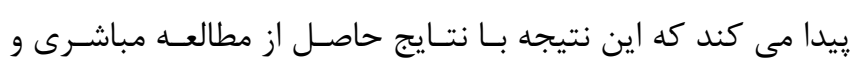

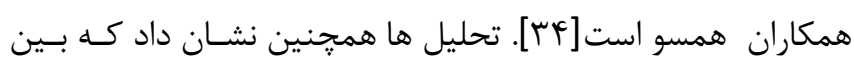

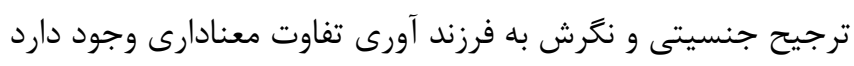

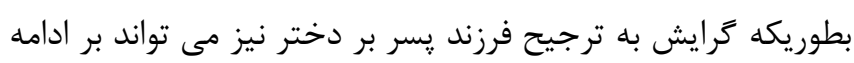




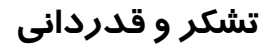

مقاله يِيش روى مستخرج از رساله دكترى تخصصى جامعه شناسى

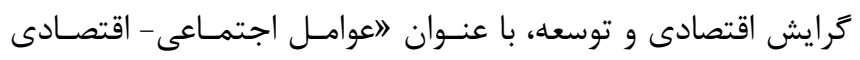

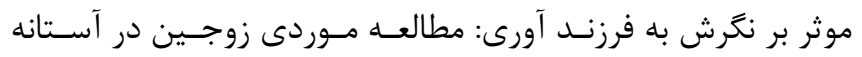

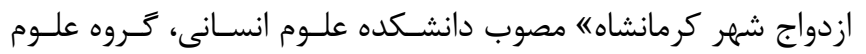

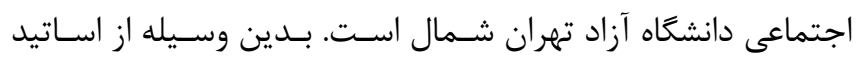
فرهيخته ترامى استاد راهنما جناب دكتر ادهمى و استاد مشاور سر

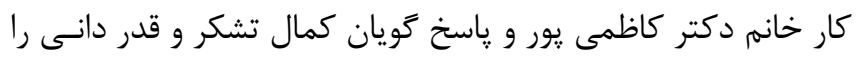

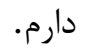
منابع

1. Abbasi Shawazi M, Razeqi Nasrabadi H, Hosseini Chavoshi M. Socio-Economic Security and Fertility Intention in Tehran City. Journal of Population Association of Iran 2020; 15: 111-238 [In Persian]

2. Sadeghi R, Abbasi Shawazi M, Farash N. Ethnicity, Ethnocentrism and Fertility: The Study of the Effects of Ethnocentrism on Fertility Intention and behavior among Kurdish and Turkish Women in Maku City. Iranian Journal of Social Studies 2018;12: 80-101 [In Persian] 3. Basten S, Sobotka T, Zeman K. Future fertility in low fertility countries.Vienna Institute of Demography Working $\quad$ Papers 2013; 5. http://hdl.handle.net/10419/97012

4. Erfani A, Jahanbakhsh R, Kalantari A. Individualism and Fertility Intentions. Journal of Population Association of Iran 2020; 15: 239-264 [In Persian]

5. Mahzoon A, Mahmoudian H,Torabi F. Relation between Social Mobility and Fertility in Iran Using Censuses and Household Income and Expenditure Surveys Data. Journal of Population Association of Iran 2019; 14: 59-84 [In Persian]

6. Abbasi Shawazi M, Razeqi Nasrabadi H, Hosseini Chavoshi M. Socio-Economic Security and Fertility Intention in Tehran City. Journal of Population Association of Iran 2020; 15: 211-238 [In Persian]

7. Soltan Z, Eini-Zinab H, Eslami M, Motlagh M. Multivariate Analysis of Iran's Period Fertility Changes in the 1370s \& 1380s. Journal of Population Association of Iran 2019; 15: 171-205 [In Persian]

8. Niazi M, Torenjipoor F, Norozi M, Asgari Kviri A. Meta-Analysis of Social Factors Affecting Fertillty in Iran. Social Development and Welfare Planning 2017; 29: 69 - 118 [In Persian]

9. Sofalchin-Langrudy A, Eini-Zinab H. Multivariate Analysis of Cross-sectional Age-specific Fertility Changes in Iran (Using Microdata Sample of the 2006

$$
\begin{aligned}
& \text { در رشته علوم اجتماعى با توجه بـهـ ماهيـت داده محـور بـودن ايسن }
\end{aligned}
$$

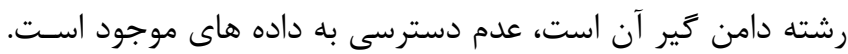

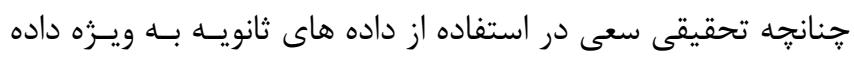

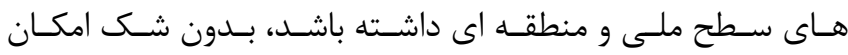

$$
\begin{aligned}
& \text { دسترسى به اين داده ها به سختى و يا در كل ميسر نيست. } \\
& \text { سهم نويسند تان } \\
& \text { عزالدين على دوستى: دانشجو، طراحى و اجراى مقاله } \\
& \text { عبدالرضا ادهمى: استاد راهنما، نوشتن مقاله } \\
& \text { شهلا كاظمى يور: استاد مشاور، نوشتن مقاله }
\end{aligned}
$$

and 2011 National Censuses). Journal of Population Association of Iran 2020; 14: 45-67 [In Persian]

10. Seifoori Toghroljerdi B, Hassani Darmian GH. Majdi A. Analyzing Fertility Indicators: A MetaAnalysis of Existing Literature. Journal of Social Sciences 2020; 16:113-145 [In Persian]

11. Kazemipour Sh, Idrisi A,Vishkaei S. Social Factors Affecting Fertility in the Family (Case Study: Married Students of Islamic Azad University, North Tehran Branch). Sociological studies of Iran, Summer 2012; 5: 57 - 75 [In Persian]

12. Foroutan Y, Karami F. Childbearing Desires in Iran: Patterns and Determinants. Journal of Population Association of Iran 2018; 11: 72-101 [In Persian]

13. Puur A, Oláh L, Tazi-Preve M, Dorbritz J. Men's Childbearing Desires and Views of the Male Role in Europe at the Dawn of the 21st Century 2008; 19: 18831912.http://www. demographic- research. Org

14. Abbasi-Shavazi M, Mahmoudian H, Sadeghi R, Ghorbani Z. The Impact of Value-Attitude Orientations on the Ideals of Childbearing in Iran. Journal of Population Association of Iran 2020; 26: 37-66 [In Persian]

15. Erfani A, Jahanbakhsh R, Kalantari A. Individualism and Fertility Intentions. Journal of Population Association of Iran 2020; 15: 239-264 [In Persian]

16. Statistical Center of Iran.Total fertility rate by total population and Iranian population. 2019-2017 [In Persian] http://www.amar.org.ir

17. Lappegard T, Ronsen M, Skrede K. Fatherhood and Fertility. Fathering 2011; 9: 103-120

18. Niazi M, Torenjipoor F, Norozi M, Asgari Kviri A. Meta-Analysis of Social Factors Affecting Fertillty in Iran. Social Development and Welfare Planning2017; 29: 69-118 [In Persian]

19. Rad F, Savabi H. Investigation on Tendency to Fertility and its Related Social Factors (A Case Study of 
Married Women Aged 15 to 50 in Tabriz). Journal of Women and Family Studies 2016; 5: 127-155 [In Persian]

20. Firooz K, Karami F. Assessment of the impact of family power structure on fertility rate in Tehran City. Women in Development and Politics 2015; 2 : 291-308 [In Persian]

21. kalbasiisfahani $F$, hashemian $B$, sarayi $I$, nikbakhsh $S$. A Sociological Analysis of Parental Attitude towards Preferential Gender Preference Based on GT Theory. The Women and Families Cultural - Eductional Journal 2020; 14:7-26 [In Persian]

22. Firoz Z, Zare B, Shamsodini H.The effect of lifestyle factors on attitudes toward childbearing, women on the verge of marriage in Tehran. Women in Development and Politics 2016; 14: 234-217 [In Persian] 23. Hashemi F, Rajabi M, Ahmadi A. Study of women's attitude toward value of children (case study: women 1549 years old of Shiraz City). Journal of Applied Sociology2017; 28: 61-78 [In Persian]

24. Arjmand I, Sahpoush I, Boroumand N. Investigation of social and cultural factors affecting the propensity to childbearing in Andimeshk City with emphasis on lifestyle (case study of married women under 35). Journal of Sociological Studies of Youth 2016; 6: 9-24 [In Persian]

25. Pezhhan A, Arab S. The social, cultural and economic factors affecting the number of ideal children among employed and unemployed women in district 8 of Tehran city. Journal of Population 2017; 22: 58-78 [In Persian]

26. Frozanfar S, Mahali F, Rahimi A, Poor Reza A.Investigating the relationship between women's empowerment and reproductive behaviors. Daneshvar 2012; 19: 1-10 [In Persian]

27. Niazi M, Torenjipoor F, Norozi M, Asgari Kviri A. Meta-Analysis of Social Factors Affecting Fertillty in Iran. Social Development and Welfare Planning 2017; 29: 69 - 118 [In Persian]

28. Seifoori Toghroljerdi B, Hassani Darmian G, Majdi A, Kermani M. Analyzing Fertility Indicators: A MetaAnalysis of Existing Literature. Journal Of Social Sciences 2020; 16: 145-113 [In Persian]

29. Abbasi-Shavazi MJ, Torabi F. Fertility and Education Female, eds (Poza-Sousa. A and, Groth. H in", Countries Islamic in. Population :Heidelberg. Jigsaw the Assembling: Countries Muslim in Dynamics $t$ Springer2012; 43-62. DOI:10.1007/978-3-642-278815_4
30. Rasoulzadeh Aghdam S, Afshar S, Adlipour S, Mohammadtabar S.Analysis of the relationship between social capital and lifestyle with tendency to childbearing (Case study: Students of Azerbaijan Shahid Madani University). Journal of Sociocultural Strategy 2017; 5; 107-35 [In Persian]

31. Enayat H, Parnian L.Study of the relationship between cultural globalization and the propensity for childbearing. Journal of Woman \& Society 2013; 4: 109136 [In Persian]

32. Bagheri A, Saadati M. Factors Affecting First and Second Birth Intervals among 15-49 Year-Old Women in Tehran. Iranin Journal of Epidimiology2019: 15: 7668 [In Persian]

33. Abbasi-Shavazi M, Khajeh Salehi Z. Assessing the impact of independence, social participation and women's education on the desire to have children in Sirjan. Journal of Women in Development and Policy 2013; 1: 45-64 [In Persian]

34. Mobasheri M, Alidosti M, Heydari S, Khosravi F, Khalfian P, Jalilian M. Determining the most important factors affecting the fertility pattern of single and childless families in Shahrekord. Journal of Ilam University of Medical Sciences 2013; 21: 63-70 [In Persian]

35. Mansurian M, Khoshnevis A. Sex preference and tendency of women to fertility. search in Tehran . Journal of Human and Social Research 2006; 24:129-46 [In Persian]

36. Hejazi N. Women's attitude to having second child and factors effecting on it . J Health Syst Res 2013; 9: 111 [In Persian]

37. Nafisi N, Zarghami $H$, Shiri $M$. Investigating the tendency to have children on the eve of marriage and some related factors in Iran. Population Quarterly 2017; 92: 1-9 [In Persian]

38. Mousavi F, Ghafelebashi M. A study of attitudes towards childbearing in young families of Qazvin city. Women and Family Studies 2014; 1: 111-34 [In Persian] 39. Samiei Nasab M, Torabi M. Indicators and population policies in Iran Second Impression Jurnal 2010; 7: 143-178 [In Persian]

40. Bahrie N, Bahrie $N$, Arabnejad B, Lotfi $H$. comparative study of women's attitudes and practices toward family planning programs in planned and unwanted pregnancies. Yazd University Research Journal 2006; 15: 61-54 [In Persian] 


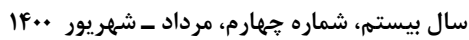
$\int_{-\infty}^{\infty}$

يرسشنامهى طرح بررسى فرزندآورى (جوانان در آستانهى ازدواج)

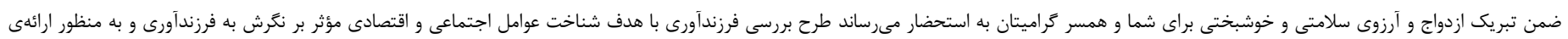

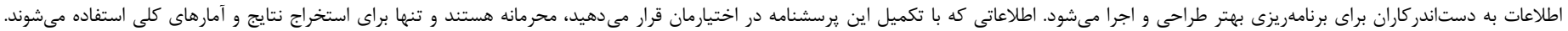
קِيشإِيش از همكارى شما سياسگزاريم.

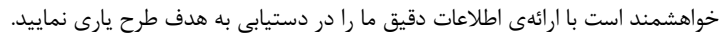

\begin{tabular}{|c|c|c|}
\hline 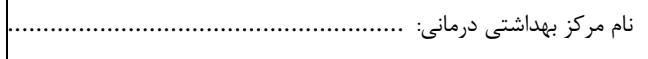 & 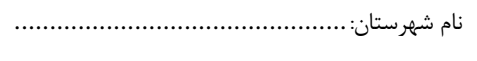 & 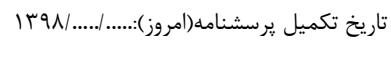 \\
\hline
\end{tabular}

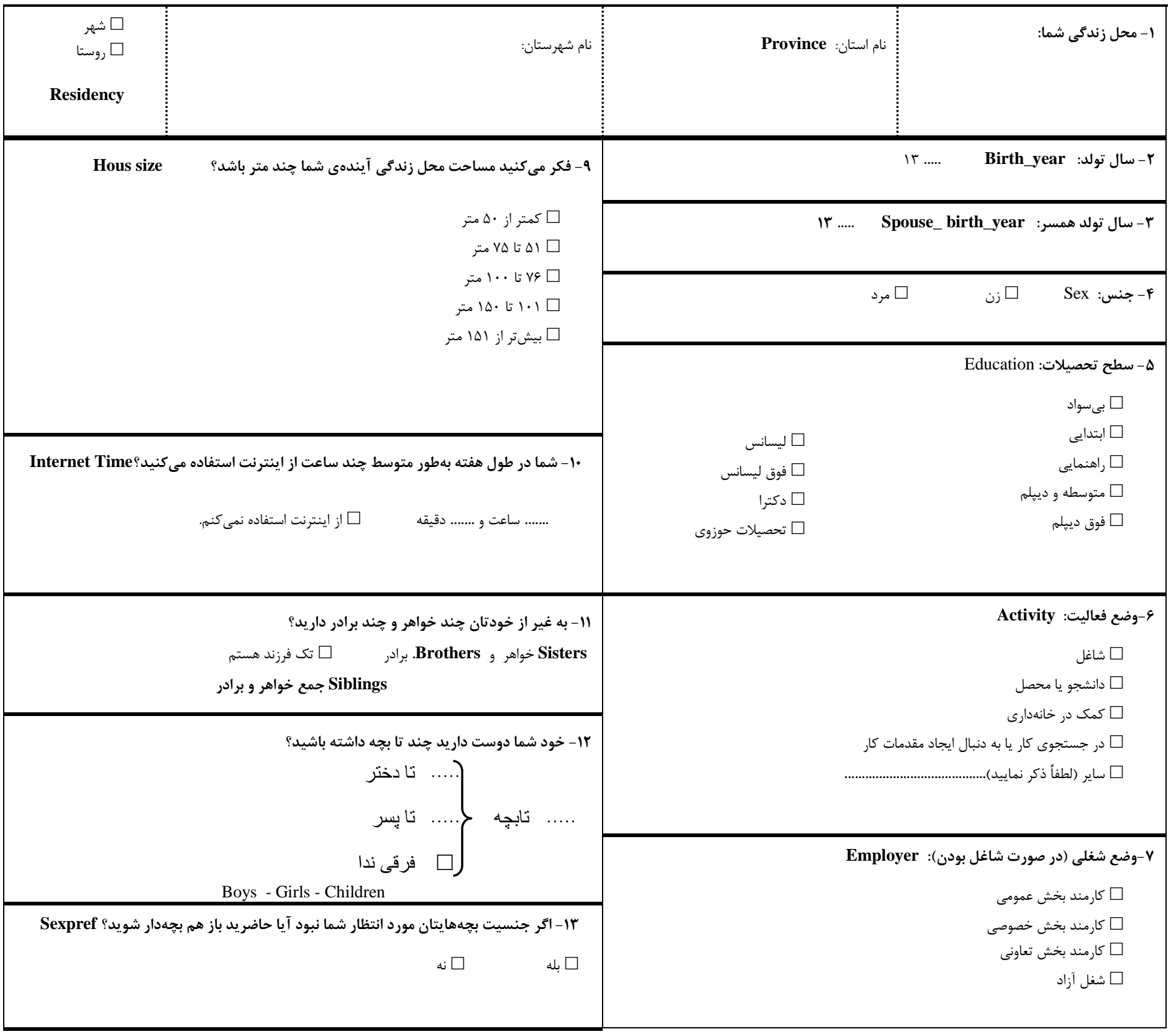


سال بيستم، شماره جهارم، مرداد ـ شهر يور ..

نشريه يروهشكده علوم بهداشتى جهاددانشعاهى

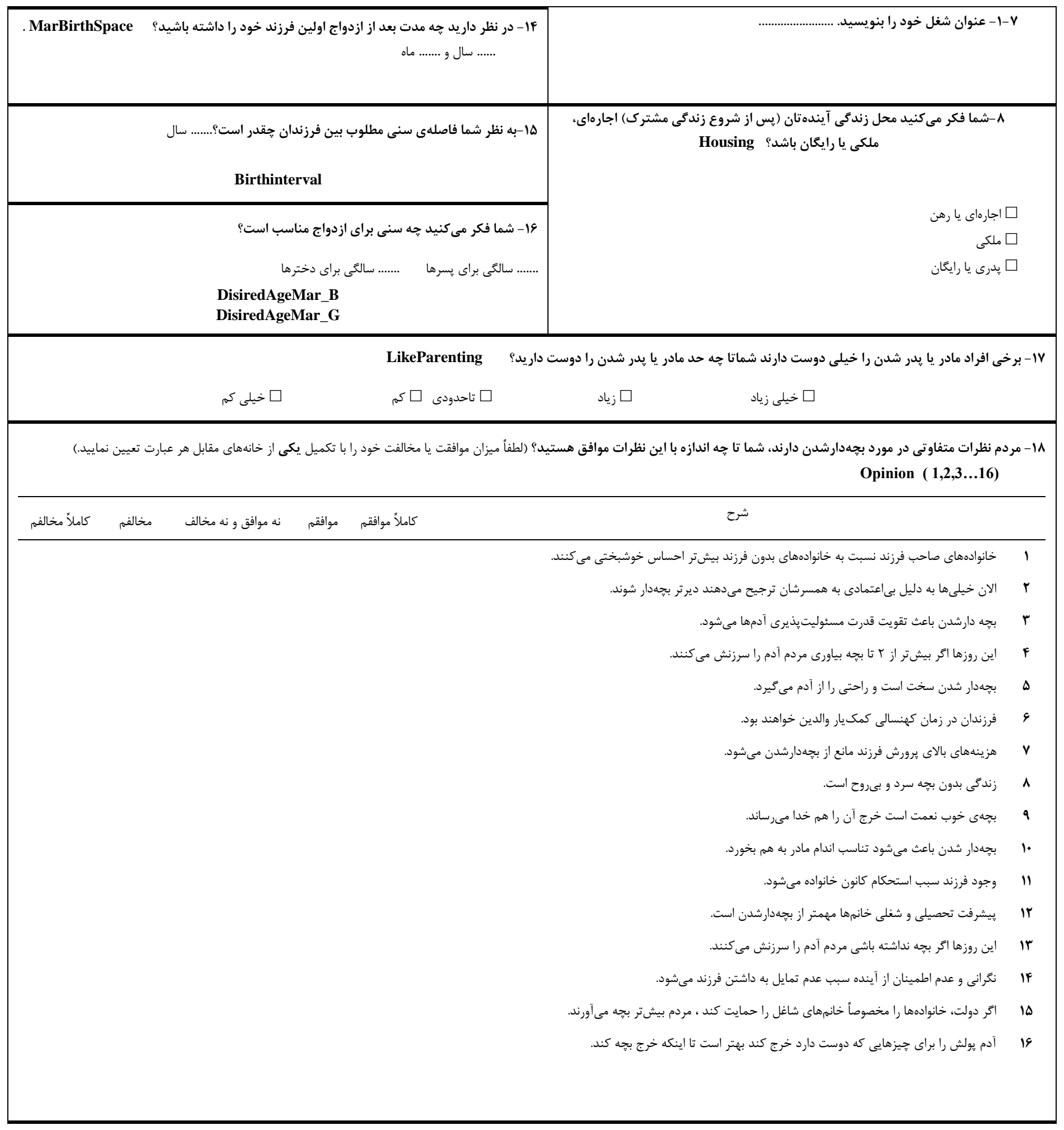




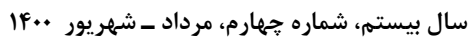
$\int_{-\infty}^{4}$

\begin{tabular}{|c|c|}
\hline 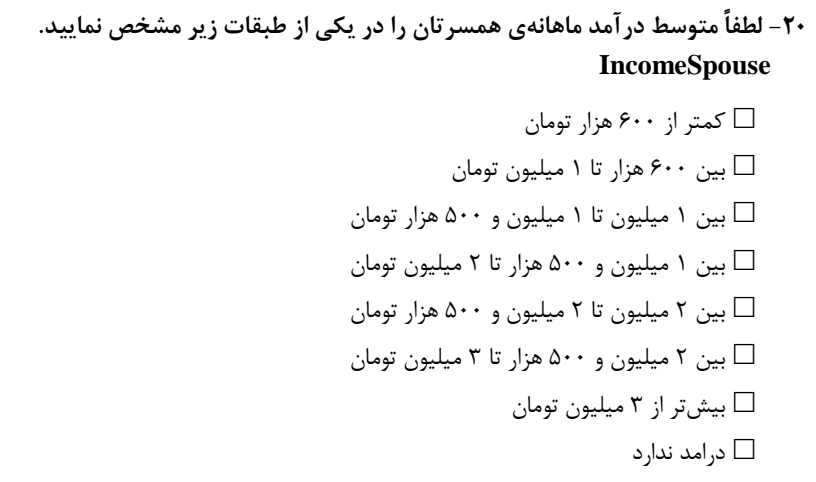 & 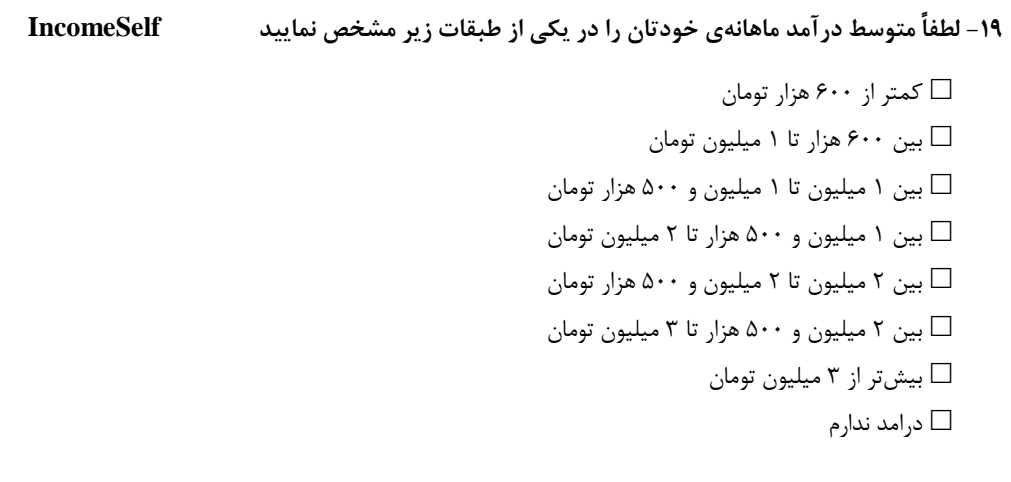 \\
\hline 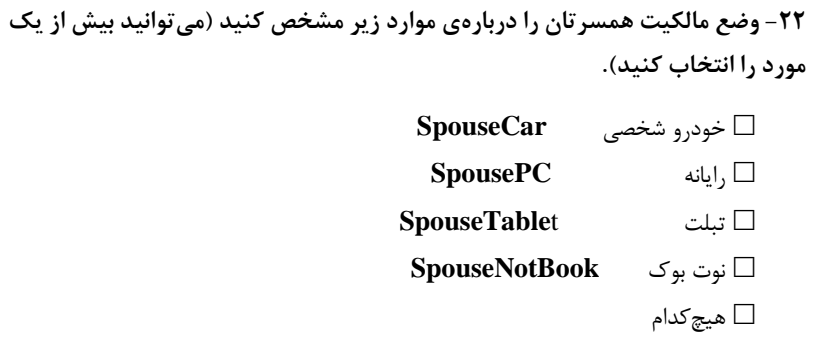 & 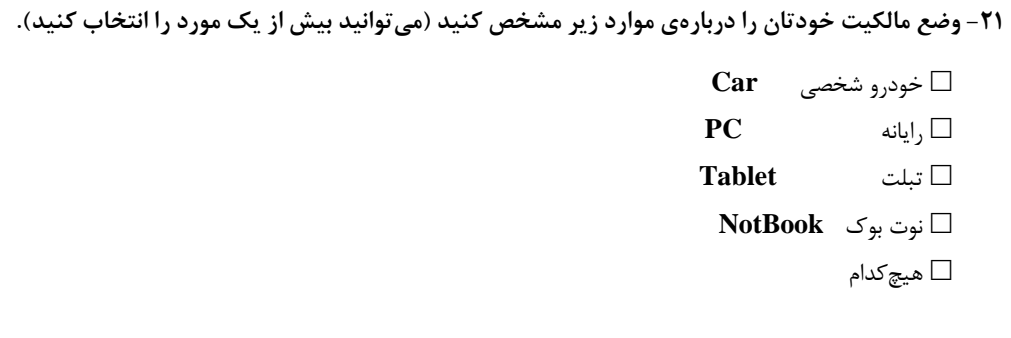 \\
\hline
\end{tabular}

